\title{
EROSION MODELING ANALYSIS FOR DWPF MFTISME TANKS
}

Si Y. Lee, Richard A. Dimenna, John R. Neuville, and Glenn A. Taylor

Savannah River Technology Center

Westinghouse Savannah River Company

Savannah River Site

Aiken, SC 29808

Prepared for the U.S. Department of Energy Under Contract Number DEAC09-96SR18500

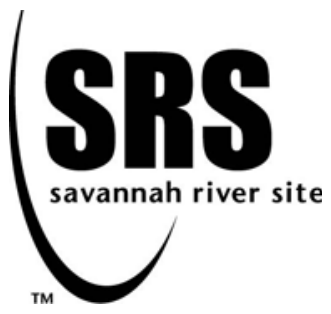


This document was prepared in conjunction with work accomplished under Contract No. DE-AC09-96SR18500 with the U. S. Department of Energy.

\section{DISCLAIMER}

This report was prepared as an account of work sponsored by an agency of the United States Government. Neither the United States Government nor any agency thereof, nor any of their employees, makes any warranty, express or implied, or assumes any legal liability or responsibility for the accuracy, completeness, or usefulness of any information, apparatus, product or process disclosed, or represents that its use would not infringe privately owned rights. Reference herein to any specific commercial product, process or service by trade name, trademark, manufacturer, or otherwise does not necessarily constitute or imply its endorsement, recommendation, or favoring by the United States Government or any agency thereof. The views and opinions of authors expressed herein do not necessarily state or reflect those of the United States Government or any agency thereof.

This report has been reproduced directly from the best available copy.

Available for sale to the public, in paper, from: U.S. Department of Commerce, National Technical Information Service, 5285 Port Royal Road, Springfield, VA 22161, phone: (800) 553-6847, fax: (703) 605-6900

email: orders@ntis.fedworld.gov

online ordering: http://www.ntis.gov/help/index.asp

Available electronically at http://www.osti.gov/bridge

Available for a processing fee to U.S. Department of Energy and its contractors, in paper, from: U.S. Department of Energy, Office of Scientific and Technical Information, P.O. Box 62, Oak Ridge, TN 37831-0062,

phone: (865)576-8401,

fax: (865)576-5728

email: $\underline{\text { reports@ adonis.osti.gov }}$ 
WSRC-TR-2003-00435

KEYWORDS:

Defense Waste Process Facility Computational Fluid Dynamics Approach

Tank Flow Model Erosion Model

\section{Erosion Modeling Analysis For DWPF MFT/SME Tanks}

Si Y. Lee, Richard A. Dimenna, John R. Neuville, and Glenn A. Taylor

SAVANNAH RIVER TECHNOLOGY CENTER

September 2003

Westinghouse Savannah River Company Savannah River Site

Aiken, SC 29808

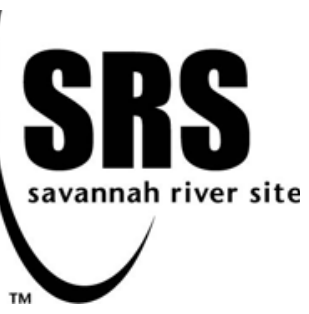


WSRC-TR-2003-00435

(This Page Intentionally Left Blank) 
This page was intentionally left blank 
WSRC-TR-2003-00435

(This Page Intentionally Left Blank) 


\section{Table of Contents}

List of Figures vii

List of Tables $\quad$ ix

Acronyms $\quad$ xi

$\begin{array}{ll}\text { Abstract } & 1\end{array}$

1. Introduction 2

2. Analysis Approach and Methodology 5

2.1 Principal Mechanisms for the Present Analysis .............................................. 7

2.2 Computational Fluid Dynamics Methodology ................................................. 7

3. Modeling Assumptions and Computational Domains $\quad 8$

4. Results and Discussions 11

5. Summary and Conclusions

6. References 33 
WSRC-TR-2003-00435

(This Page Intentionally Left Blank) 


\section{List of Figures}

Figure 1. Modeling geometry considered for the present analysis ............................... 4

Figure 2. Modeling domains considered for the present analysis .................................. 6

Figure 3. SME cooling coil guide pins maintaining the original geometry (Case-A) ............10

Figure 4. One-pin SME cooling coil guide simulating the eroded geometry identified by the recent inspection (Case-B) ............................................................. 10

Figure 5. Three-dimensional meshes used for the present computations for the Case-A study

Figure 6. Wall shear distributions for $65 \mathrm{rpm}(0.65 \mathrm{~m} / \mathrm{sec})$ with $60^{\circ}$ flow incidence -

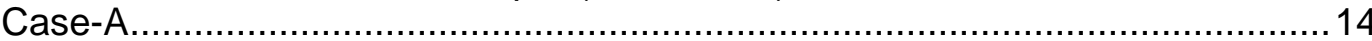

Figure 7. Wall shear distributions for $130 \mathrm{rpm}(1.5 \mathrm{~m} / \mathrm{sec})$ with $60^{\circ}$ flow incidence -

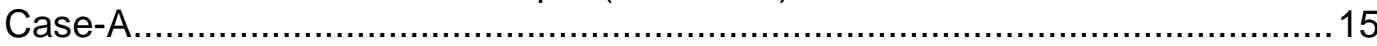

Figure 8. Comparison of wall shear distributions for $130 \mathrm{rpm}(1.5 \mathrm{~m} / \mathrm{sec})$ between $60^{\circ}$ and $30^{\circ}$ flow incidences - Case-A ............................................................. 16

Figure 8a. Comparison of the predicted high wall shear indicated on the right lead-in plate (above) to the worn-away lead-in plate shown in the visual inspection photo (below) (the model predictions based on $130 \mathrm{rpm}$ and $30^{\circ}$ flow incidence)

Figure 9. Comparison of erosion patterns due to particle impingement for two different agitator speeds with $60^{\circ}$ incident angle into the coil guide area - Case-A..........18

Figure 10. Flow patterns around the SME guide pin for $30^{\circ}$ incident angle and $65 \mathrm{rpm}$ $(0.65 \mathrm{~m} / \mathrm{sec})$ - Case-A

Figure 11. Comparison of wall shear distributions for two incident angles of slurry flow fields created by $130 \mathrm{rpm}(1.5 \mathrm{~m} / \mathrm{sec})$ agitator speed under the damaged coil guide geometry (Case-B)

Figure 12. Flow patterns around the one-pin SME guide for $130 \mathrm{rpm}$ with $60^{\circ}$ incidence $(1.5 \mathrm{~m} / \mathrm{sec})$ - Case-B

Figure 13. Comparison of abrasive wall shears for two different incident angles of slurry flow into the guide pin under the flow field created by $65 \mathrm{rpm}$ agitator speed in the damaged coil guide (Case-B)

Figure 14. Comparison of wall shears between two cases for $103 \mathrm{rpm}$ with $30^{\circ}$

incidence angle of slurry flow into the guide pin $(1.2 \mathrm{~m} / \mathrm{sec})$

Figure 15. Comparison of flow patterns between two cases for $103 \mathrm{rpm}$ with $30^{\circ}$

incidence angle of slurry flow into the guide pin $(1.2 \mathrm{~m} / \mathrm{sec})$

Figure 16. Comparison of flow rotations between two cases for $103 \mathrm{rpm}$ with $30^{\circ}$

incidence angle of slurry flow into the guide pin $(1.2 \mathrm{~m} / \mathrm{sec})$ 25

Figure 17. Comparison of erosion patterns due to the particle impingement for $103 \mathrm{rpm}$ with $30^{\circ}$ incidence angle of slurry flow into the guide pin $(1.2 \mathrm{~m} / \mathrm{sec})$................26

Figure 18. Comparison of abrasive wall shears between three different cases with $30^{\circ}$ incidence angle of slurry flow into the guide pin - Case-A.

Figure 19. Erosion distributions due to the particle impingement for the flow fields created by three different agitator speeds with $30^{\circ}$ incidence angle of slurry flow into the guide pin area under the original coil guide geometry (Case-A) .....28

Figure 20. Particle trajectories for $65 \mathrm{rpm}(0.65 \mathrm{~m} / \mathrm{sec})$ around the coil guide with $30^{\circ}$ incidence angle of slurry flow into the guide pin of the original geometry (Case-A) 
WSRC-TR-2003-00435

(This Page Intentionally Left Blank) 
WSRC-TR-2003-00435

\section{List of Tables}

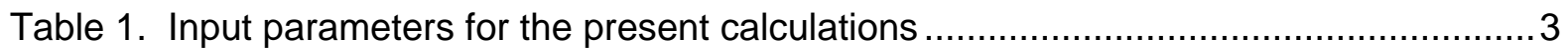

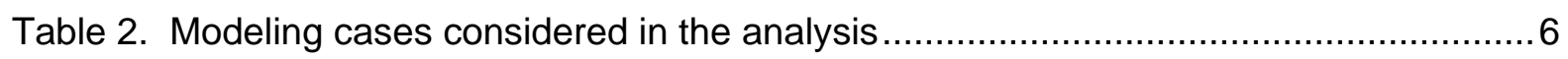

Table 3. Maximum wall shears for three major erosion locations observed by the recent SME inspections and CFD modeling results for SME/MFT coil guide (Refer to Fig. 18) 
WSRC-TR-2003-00435

(This Page Intentionally Left Blank) 


\section{Acronyms}

\begin{tabular}{ll}
\multicolumn{2}{l}{ Acronyms } \\
CFD & Computational Fluid Dynamics \\
DOE & Department of Energy \\
DWPF & Defense Waste Processing Facility \\
HLWE & High Level Waste Engineering \\
MFT & Melter Feed Tank \\
rpm & Rotations Per Minute \\
sg & Specific Gravity \\
SME & Slurry Mix Evaporator
\end{tabular}


WSRC-TR-2003-00435

(This Page Intentionally Left Blank) 


\section{Abstract}

In support of an erosion evaluation for the cooling coil guide and its supporting structure in the MFT vessel, computational models were developed to identify potential sites of high erosion. Two mechanisms were considered to evaluate high erosion locations representative of the actual flow process in the coil guide of the MFT vessel, abrasive erosion which occurs by high wall shear of viscous liquid, and chip-off erosion which is mainly governed by particle impingement.

The results show that primary locations of the highest erosion due to the abrasive wall erosion are at the leading edge of the guide, the tank floor below the insert plate of the coil guide support, and the upstream lead-in plate. The modeling results are consistent with the observed damage to the coil guide of the SME vessel. The modeling results show a good comparison between the observed erosion sites and the calculated locations of high shear regions, as well as the degree of erosion and the calculated shear stress. It is noted that the loss of the leading edge of the coil guide due to the erosion damage during the SME mixing operation does not affect the erosion patterns on the tank floor.

Calculations for the lower impeller speed in the MFT showed similar erosion patterns but significantly reduced wall shear stresses. Comparisons with SME measurements indicated that no significant erosion of the tank floor in the MFT is to be expected. 


\section{Introduction}

A visual inspection of the Slurry Mixer Evaporator (SME) tank interior done recently revealed that a leak had developed on the tank floor where the cooling coil guide is located because of erosion [1]. High Level Waste Engineering (HLWE) has continued to investigate the tank erosion in an attempt to identify the root cause so that corrective actions can be taken. Figure 1 is a modeling geometry including the cooling coil guide pins and geometrical shapes of the guide structure.

The primary cause of the tank leakage was identified as material degradation due to wear. Erosion in the SME has occurred in localized area around the coil guides. There are four coil guides located in the bottom of the tank as shown in Fig. 1. Each coil guide has similar erosion characteristics. A recent inspection conducted by DWPF Engineering identified severe erosion to the leading edge of the guide, scouring of the base metal, and loss of the top lead-in plate. The guides protrude into the flow stream and can cause a vortex that can tend to scour the exposed surfaces of the guides. This generates secondary flow circulation and results in waste fluid staying in contact with the downstream horizontal surface below the coil support insert (see Fig. 1). When solidsladen slurry comes in contact with the wall surface, it can remove wall material. This phenomenon is called erosion. It is caused by mechanical interactions of the ambient fluid and solids against the wall surface.

In the previous work $[2,3,4]$ a literature survey was performed to identify the principal mechanisms of wear for a solids laden fluid and to find out what other wear studies and experiments have been done. Available evidence suggests that the key to understanding erosion in flow systems is a detailed knowledge of the coupled and complex phenomena of solids circulation and fluid motion. One problem arising from slurry flow is the wear it creates on the tank wall. That wear occurs from the abrasive solids in the slurry and the wall shear of viscous liquid, which causes erosion. The chemicals in the slurry may result in corrosion and a synergistic effect of both erosion and corrosion. In this work, the erosion mechanism without any chemical reactions is considered as the primary cause of wear in order to simplify the problem. This simplification is justified by a material study done on the damaged tank surface which concluded that corrosion was unlikely [7].

This report presents the application of computational fluid dynamics (CFD) methods to qualitative estimate of the erosion phenomena expected in the actual SME and MFT (Melter Feed Tank) process facilities by calculating erosion drivers. Using the transport equations governing the slurry flow, two erosion mechanisms were considered to evaluate high erosion sites and to investigate the primary cause of erosion damage for the modeling domain representative of the actual mixing process in the SME/MFT vessels. One of the two erosion mechanisms is the abrasive erosion which is worn by high wall shear of viscous liquid or by continuous contact or low-angle collision of the moving solids with rough surface, and the other is the chip-off erosion which is mainly governed by high-angle impingement of particles. Ductile wall material such as stainless steel is damaged by wall mechanism when particles are impinged on the ductile surface of the present coil guide geometry with wide-open space and no closed- and curvedflow path. The previous results [2] show that the primary locations of high erosion due to particle impingement are at the occurrence of sudden change of flow direction, sudden contraction, and flow obstruction. 
For the present work, Eulerian continuous transport equations for the stream flow and Lagrangian momentum balance for the solid phase dispersed in the continuous steam flow were used to estimate wall shear and particle-impinged erosions. For typical operating conditions of the facility, Reynolds number is about $10^{5}$ in terms of tank diameter. It corresponds to a fully turbulent flow regime. A two-equation turbulence model was used to consider the dispersion effect of particles due to turbulent eddies. In the analysis, flow patterns, wall shear, and vorticity distributions were considered as the key parameters for capturing flow characteristics and providing information on potential damage sites caused by abrasive erosion.

A key concern with radioactive operation of a piping system is the integrity of the tank, cooling coil fittings, and accompanying equipment. A breach could release contamination, which at a minimum would increase operational costs due to clean up and down time, but more importantly, would increase the potential radiation exposure to personnel. It is very important to thoroughly understand the effects of erosion caused by slurry flow so that proper maintenance can minimize equipment failure and guarantee safe operation.

The primary objective of the present work is to identify potential locations of high erosion for the SME/MFT coil guides and its support structures as shown in Fig. 1. The SME and MFT are similar process vessels with nearly identical geometry. Both vessels have coil banks and identical agitators, but they don't have any baffles. The agitator is located at the center of the tank and has two impellers. The upper blade is a propeller to circulate fluid in the axial direction. The lower blade is a Rushton-type flat-plate impeller. This type of impeller directs flow in the radial direction. The SME agitator operates at 130 and $65 \mathrm{rpm}$, whereas the MFT agitator operates at $103 \mathrm{rpm}$ and $65 \mathrm{rpm}$.

Table 1 shows typical conditions for key operating parameters of the SME and MFT tank operations in DWPF facility. This information will be used in the present modeling calculations.

Table 1. Input parameters for the present calculations

\begin{tabular}{|c|c|c|}
\hline \multicolumn{2}{|c|}{ Parameters } & Input data \\
\hline \multicolumn{2}{|c|}{ Bulk fluid specific gravity } & $1.35 \mathrm{sg}$ \\
\hline \multicolumn{2}{|c|}{ Fluid viscosity } & $10 \mathrm{cp}$ \\
\hline \multicolumn{2}{|c|}{$\begin{array}{l}\text { Fluid velocity at the model boundary } \\
\text { (agitator speed) }\end{array}$} & $\begin{array}{c}0.65 \mathrm{~m} / \mathrm{sec}(65 \mathrm{rpm}), 1.8 \mathrm{~m} / \mathrm{sec}(130 \mathrm{rpm}), \text { and } \\
1.3 \mathrm{~m} / \mathrm{sec}(103 \mathrm{rpm})\end{array}$ \\
\hline \multirow{3}{*}{$\begin{array}{l}\text { Solid particle } \\
\text { (frit) }\end{array}$} & Average diameter & 100 microns \\
\hline & Density & $2.43 \mathrm{gm} / \mathrm{cc}$ \\
\hline & Solid fraction & $30 \mathrm{wt} \%$ * \\
\hline
\end{tabular}

Note: *This corresponds to 19.2 vol.\% solids in fluid. 


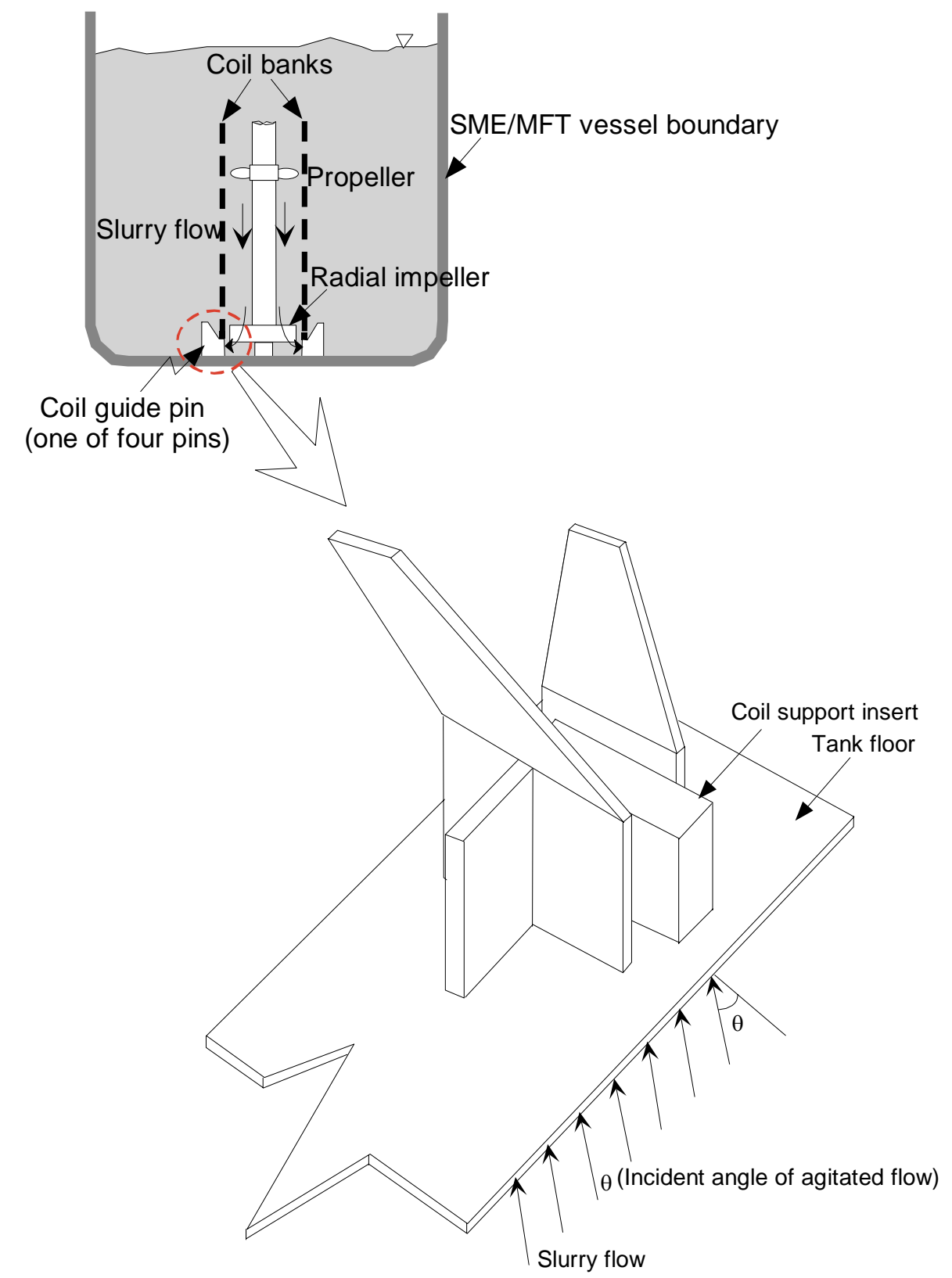

(Original geometry of coil guide and support)

Figure 1. Modeling geometry considered for the present analysis 


\section{Analysis Approach and Methodology}

The present analysis focuses on the flow behavior in the vicinity of the coil guide and its supporting structure. The analysis work took a Computational Fluid Dynamics (CFD) approach by using a commercial software, Fluent ${ }^{\mathrm{TM}}$. Due to the complexities of the erosion process, accurate quantitative results are not expected from the CFD model without test against which to compare. However, the modeling results will be used to evaluate the potential for excessive erosion at the base of the MFT coil guide. The present CFD modeling is used in a qualitative way to investigate the high erosion locations near the cooling coil guide and its supporting structure by observing the existence of erosion drivers. In addition, the CFD results will help to understand the damage mechanisms associated with erosion phenomena.

Figure 2 shows the modeling and computational domains used for the present analysis including the original guide pin geometry in the SME tank. The computational domain was deliberately kept small to minimize the size of the numerical model and the associated computational time. Nonetheless, upstream flow information was included from the global model to ensure the flow pattern reaching the domain boundary of the SME guide pin would be close to that actually occurring in the tank mixed with agitator. Because of the close proximity of the coil guides to the discharge of the radial impeller and the tendency of the cooling coils to isolate the impeller inlet flow from the outer annulus of the tank, the inlet flow to the guide pin model is not affected by the flow past the guide pin. Therefore, the global model gives a good approximation to the boundary flow for the current model.

Thus, two stages of modeling efforts were made. One is the global model, which includes the mechanical agitator and tank boundary in the computational domain to evaluate upstream flow field of each coil guide and to estimate overall flow patterns near the boundary of the cooling coil guide under different rotational speeds of the SME or MFT Agitator. The flow field calculations of the global model were performed by Fluent ${ }^{\mathrm{TM}}$ MixSim code. The second stage created a detailed model to evaluate the flow field surrounding the coil guide. The boundary conditions for this model were based on the information provided from the first model.

The modeling results performed here will be used in identifying the potential locations of high erosion for the SME coil guide and its support structure and in estimating the maximum allowable speed of the MFT agitator. In this case, two different modeling domains were used to examine how sensitive the results of flow patterns are to the geometrical change of the coil guide as shown in Fig 1.

Based on the modeling domains defined in Fig. 2 and the operating conditions shown in Table 1, the erosion evaluations for two different modeling cases of the cooling coil guide were performed to provide information on erosion damage causes for the areas near the four cooling coil guides and to examine how sensitive flow patterns and high erosion locations are changed due to the disappearance of flow obstructions such as the leading-in plate as result of the erosion process. The modeling objectives for the two modeling cases are summarized in Table 2. 


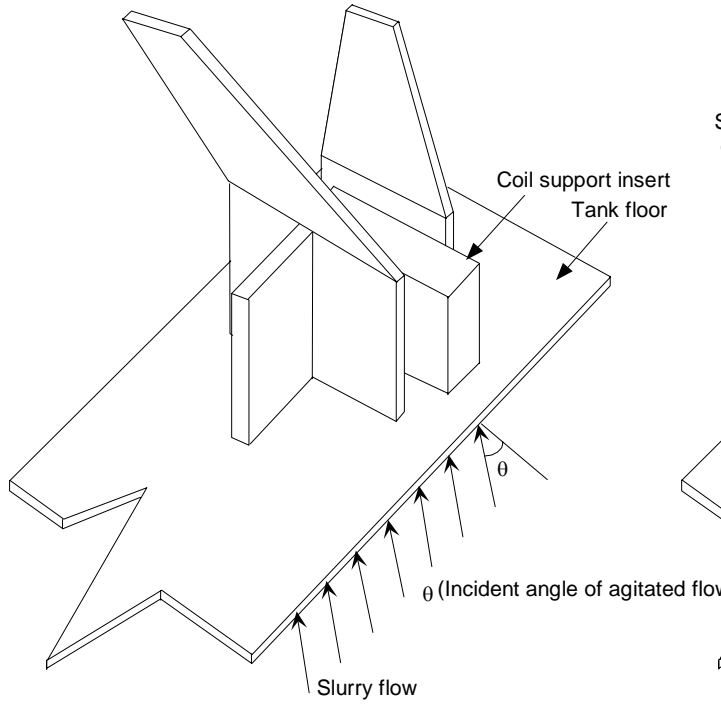

(Original geometry of coil guide and support)

(Case-A)

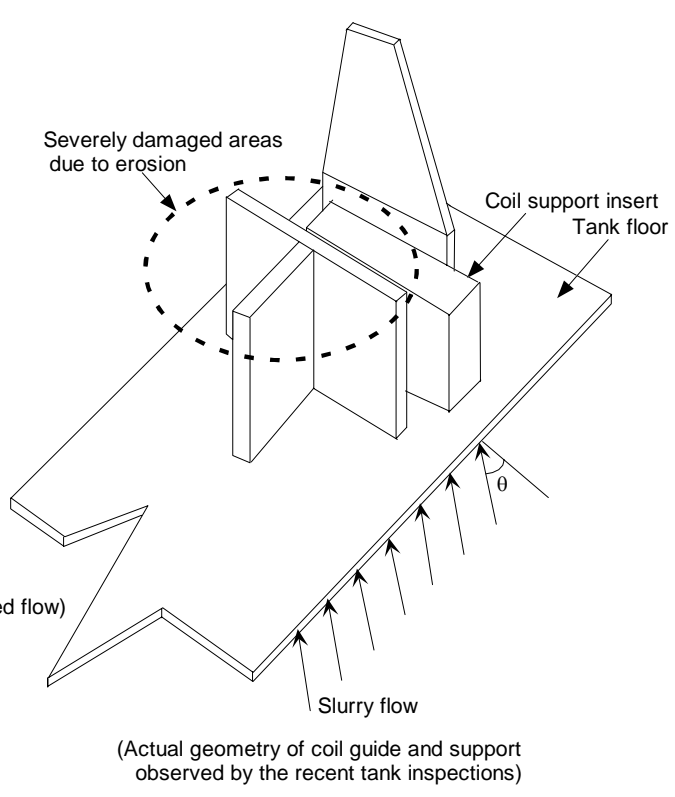

(Case-B)

Figure 2. Modeling domains considered for the present analysis

Table 2. Modeling cases considered in the analysis

\begin{tabular}{|c|l|l|}
\hline Modeling cases & \multicolumn{1}{|c|}{$\begin{array}{c}\text { Modeling domain } \\
\text { (shown in Fig. 2) }\end{array}$} & \multicolumn{1}{c|}{ Primary objective } \\
\hline Case-A & $\begin{array}{l}\text { Original undamaged coil } \\
\text { guide obstructions in the } \\
\text { flow domain }\end{array}$ & $\begin{array}{l}\text { To estimate flow patterns associated with } \\
\text { abrasive erosion due to wall shear }\end{array}$ \\
\hline Case-B & $\begin{array}{l}\text { Actual damaged coil } \\
\text { guide obstructions as } \\
\text { observed in the flow } \\
\text { domain }\end{array}$ & $\begin{array}{l}\text { To examine how sensitive flow patterns } \\
\text { and high erosion locations are changed } \\
\text { due to the loss of flow obstructions during } \\
\text { the erosion process }\end{array}$ \\
\hline
\end{tabular}




\subsection{Principal Mechanisms for the Present Analysis}

As stated earlier, the principal mechanisms of erosion for a slurry were identified. These are the solids content of the working fluid, regions of secondary flow recirculation and particle impingement with the component walls, and regions of high wall shear.

The current erosion analysis addresses flow patterns expected for the coil guide geometry, as well as the specific erosion mechanisms for a slurry flow, wall shear stress and particle impingement. Particle concentration of the mixed fluid is about 19 volume percent corresponding to $30 \mathrm{wt} \%$ particles. The average primary flow velocity is in the range of 0.65 to $1.5 \mathrm{~m} / \mathrm{sec}$ as shown in Table 1 . These velocities were derived from the flow field results of the global model. The suspension slurry is assumed to flow like a homogeneously-mixed flow since the flow regime is fully turbulent due to presence of agitator located at the center of the SME or MFT vessel.

The models assume that the erosion process with a homogeneous solid-fluid flow regime is caused mainly by abrasive wall friction since the solids laden by the viscous fluid of about $10 \mathrm{cp}$ may not separate from the bulk fluid motion. Ductile wall material such as Hastalloy or stainless steel is damaged by wall mechanism when particles are impinged on the surface of the present coil guide geometry with wide-open space and no closed- and curved- flow path. The previous results [2] show that the primary locations of high erosion due to particle impingement are at the occurrence of sudden change of flow direction, sudden contraction, and flow obstruction. Thus, for a slurry flow with solids content, the particle impingement process may not be important compared to the abrasive shear-driven erosion mechanism since the solid-fluid mixture flows like a homogeneous fluid due to the high interfacial drag. In addition, the present coil guide geometry has a large open space without any sudden change of flow direction.

\subsection{Computational Fluid Dynamics Methodology}

As discussed earlier, main mechanisms for erosion were identified to develop simulation methods using a CFD approach and the commercial CFD code, Fluent ${ }^{\mathrm{TM}}$ [8]. Two basic models were developed for the present analysis. One is the original undamaged geometry model based on abrasive wall erosion of ductile materials such as Hastalloy and stainless steel. Its purpose is to find the locations of high wall shear for the modeling domain of the original geometry of the coil guide as shown in Figs. 2. The other model is based on the actual geometry of the damaged coil guide to examine the sensitivity of flow patterns and high erosion loactions due to the geometrical change inside the modeling domain. In addition, the models were also coupled with particle transport to characterize the erosive slurry flow patterns and investigate the locations of high erosion caused by particle impingement for the selected modeling domains.

The present methodology for both models relies on an assumption that material erosion is governed primarily by the wall shear mechanism when particles are homogeneously distributed in the slurry flow and the impingement angles of the particles against the wall surface are small. The wall shear model will be used to provide qualitative information on flow patterns and potential erosion damage locations. 
For the calculations of the continuous slurry flow field, three-dimensional transport and continuity equations were solved in an Eulerian reference system. Detailed governing equations for the continuous phase were provided in the previous work [13]. Reynolds number for the flow condition is found to be in the range of about $10^{5}$, which corresponds to a fully turbulent regime. A two-equation turbulence model with turbulent kinetic energy and dissipation equations, the $\kappa-\varepsilon$ model, was used to include the effects of particle dispersion due to turbulent eddies in the continuous phase. For the wall shear model, field solutions for the Eulerian equations of the continuous slurry flow were applied to estimate wall shear stress. To simulate particle impingement trajectory, a momentum balance, including inertia, solid-fluid interfacial drag, and gravitational terms, was used in a Lagrangian reference system to calculate the trajectory of the discontinuous particles in the slurry. Thus, a Lagrangian-formulated deterministic particle equation of motion was solved via an integral method to predict particle speeds and trajectories once the continuous flow field was known. All converged solutions for the governing equations were achieved using the segregated and iterative solution technique.

As discussed above, two erosion mechanisms were considered to evaluate the high erosion locations and investigate the primary cause of wear damage in the modeling domain representing flow in the region of the cooling coil guide. Flow patterns, wall shear, and vorticity distributions were considered key parameters for capturing flow characteristics and potential leakage sites caused by erosion damage.

\section{Modeling Assumptions and Computational Domains}

Assumptions in the erosion calculations were as follows:

- The present models consider only mechanical erosion related to the loss of material from the wall surface, but they do not consider the moving boundary effects due to the material loss.

- The present analysis deals with pure erosion due to the hydrodynamic interactions of waste flow against the wall boundary so that chemical corrosion was not considered.

- The waste flow regime is assumed to be fully turbulent, and particles are distributed homogeneously. Reynolds number is in the range of $10^{5}$ based on the design and operating conditions, and average flow velocity of fluid-solid flow is much larger than the critical entrainment velocity of solid particle.

- Waste fluid is assumed to have Newtonian behavior.

- The entire domain is isothermal so that no energy balance equation is considered. Steam condensation within the modeling boundary is assumed to be negligible since cooling across the modeling boundary is small.

- The frit particles are assumed to be elastic in the sense that no kinetic energy is dissipated as a result of the collision against the wall surface. This is realized through a coefficient of restitution, which is the ratio of the approach to recoil velocities and is specified as an input parameter to the code. In the present analysis, when a particle impinges a wall boundary, this ratio is assumed to be unity 
so that both the normal and tangential conditions result in no momentum (or energy) dissipation.

- The particle-particle interactions and the effects of the particle volume fraction on the continuous fluid phase are negligible.

- The particle shape contained in a waste flow is assumed to be spherical. The particle size is uniform and about 100 microns in diameter on the average as provided by the customer.

- The particles have no direct impact on the generation or dissipation of turbulence in the continuous phase.

Three-dimensional computational mesh for one of the modeling domains, as shown in Figs. 3 and 4, is presented in Fig. 5. A finer non-uniform grid was used in the corner zones and joint sections at which potential flow direction changes and flow splits might occur. From the nodalization study, an optimum number of about 100,000 nodes was established for the final analysis of the three-dimensional erosion model. As shown in the figures, very fine meshes, less than 0.05 in long, were used near the misalignment and connection joints to capture the high velocity gradient. Flow boundary conditions at the inlet of the computational flow domain used uniform homogeneous flow since the distance prior to the inlet of the present modeling domain was long enough to reach fully-developed flow.

Based on the modeling assumptions, the continuous and discrete phase equations are coupled to compute the particle trajectories and find the locations of high wall friction where the highest erosion is assumed to occur. The three-dimensional computational model was developed and solved with Fluent ${ }^{\mathrm{TM}}$ [8]. All converged solutions were achieved using the segregated and iterative solution technique. 


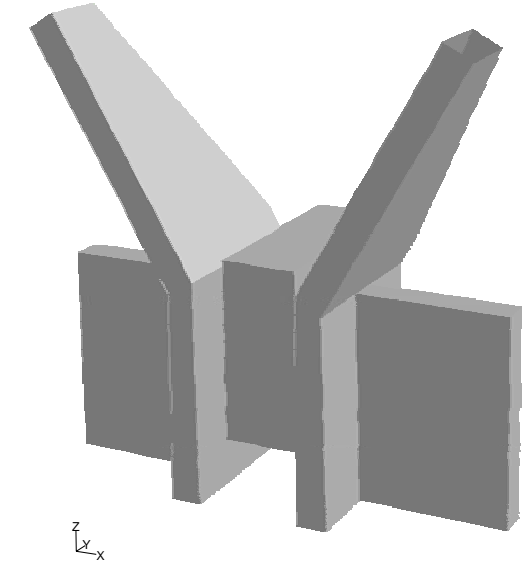

(Side view)

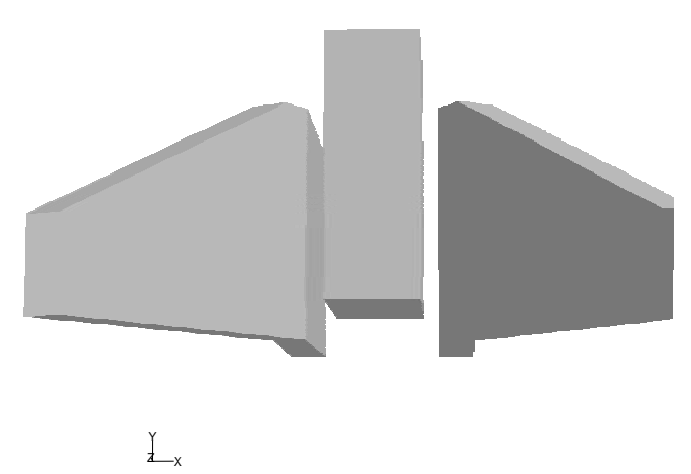

(Top view)

Figure 3. SME cooling coil guide pins maintaining the original geometry (Case-A)
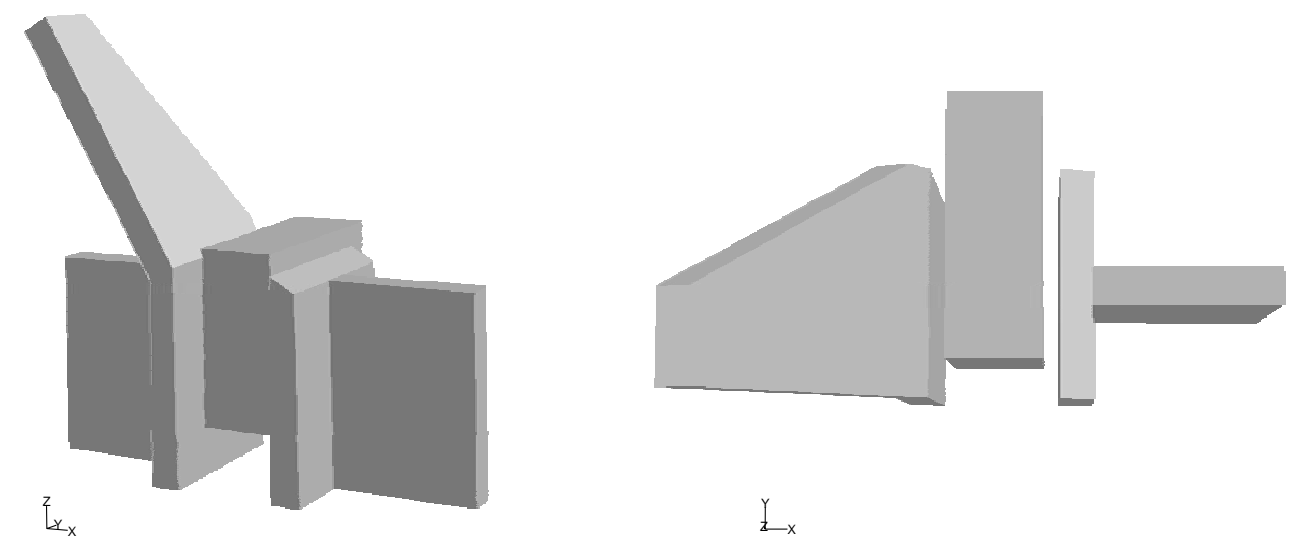

(Side view)

(Top view)

Figure 4. One-pin SME cooling coil guide simulating the eroded geometry identified by the recent inspection (Case-B) 


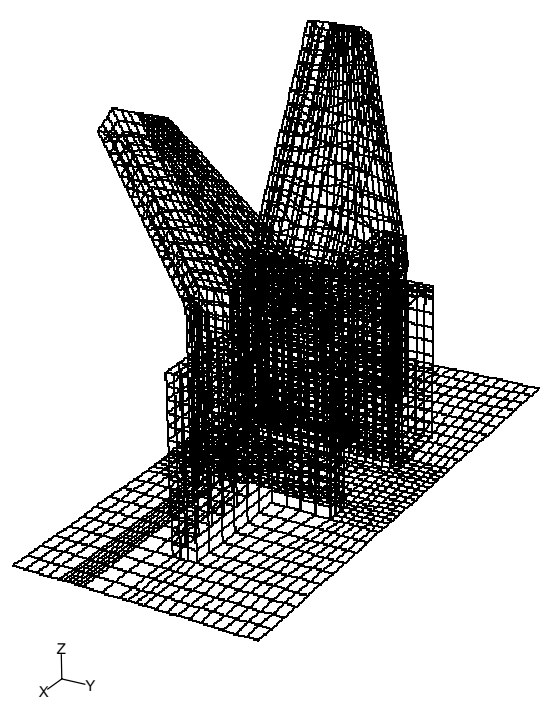

Figure 5. Three-dimensional meshes used for the present computations for the Case-A study

\section{Results and Discussions}

Based on the modeling domain defined in Figs. 3 and 4 and the operating conditions shown in Table 1, the erosion evaluations for two different modeling domains of the MFT coil guide were performed by a computational approach to provide information on erosion damage causes of the areas near the four coil guides [10]. The boundary conditions provided in Table 1 were based on the results of the tank flow model, which considered the rotational motion of the agitator in the SME or MFT vessel. As shown in Figs. 6 and 7, the results of wall shear distributions for the Case-A modeling domain are compared between two different velocities with $60^{\circ}$ flow incidence into the coil guide region. The results show that the locations of high erosion sites are not changed when the velocity is increased. The high erosion sites are not sensitive to the variations of incident angles, but the $30^{\circ}$ incident flow field creates an overall erosion patterns closer to the one observed by the recent inspections. When the incidence angle of flow is changed from $60^{\circ}$ to $30^{\circ}$, wall shears on the front lead-in plate and the tank floor regions in front of the lead-in plate and below the coil support are increased (more red areas in the upstream region in Fig. 8) because of the increased radial flow motion at the boundary surface. The results are compared under the original configurations of the coil guide shown in Fig. 8. It is noted that the predictions of high erosion sites are consistent with the ones observed by the recent inspections [11] as shown in Fig. 8a. 
The predicted results by the particle collisions against the solid surface of the coil guide are shown in Fig. 9. The pattern of high impingement region is qualitatively different from the observed wear patterns in the SME. Therefore, particle impingement was not identified as the principal wear mechanism. Flow patterns for the original coil guide area are shown in Fig. 10. The figure shows that the region near the tank floor area between the lead-in plates has the highest flow corresponding to one of the high erosion sites as observed by the recent inspections.

The modeling results for the damaged geometry of Case-B are compared with that of the undamaged geometry of Case-A to examine how sensitive high erosion sites are to the change of geometrical shape. Figure 11 compares wall shear distributions for two incident angles of the slurry flow fields created by $130 \mathrm{rpm}$ agitator speed under the damaged coil guide geometry, Case-B. The results show that when the radial speed increases with the decrease of incident angle, the abrasive wall shears at the upstream side of the coil guide floor and at the tank floor below the insert plate of the coil guide increase. The flow patterns for the $60^{\circ}$ incident angle and $1.5 \mathrm{~m} / \mathrm{sec}$ flow velocity are shown in Fig. 12.

It is noted that the erosion patterns are not sensitive to the flow fields near the coil guide and the geometrical configurations of the coil guide as shown in Figs. 13 and 14. The corresponding flow patterns and fluid vorticity distributions around the original and damaged structures of the coil guide are compared in Figs. 15 and 16. In these figures the upstream region between the guide support and coil support insert has the highest flow rotations. Comparison of erosion patterns due to the particle impingement for the $1.2 \mathrm{~m} / \mathrm{sec}$ incident flow velocity with $30^{\circ}$ incidence angle of slurry flow into the guide are made in Fig. 17.

A series of the modeling results demonstrates that the loss of the leading edge of the coil guide due to the erosion damage during the SME mixing operation is not sensitive to the erosion patterns, and the radial flow contribution to the location of erosion site is found to be insignificant. The sites of high abrasive erosion and the degree of erosiondriven damage due to wall shear mechanism for three typical flow conditions shown in Table 1 are compared in Fig. 18. The quantitative results for three high erosion sites are compared among three different speeds of the tank agitator in Table 3 . The results demonstrate that when the MFT agitator operates between $65 \mathrm{rpm}$ and $103 \mathrm{rpm}$, the leading edge of the coil guide will be damaged by the abrasive wall erosion, but maximum wall shear for the MFT tank floor below the coil tab is about $87 \mathrm{~Pa}$, which is well below the seriously eroded value of about $169 \mathrm{~Pa}$ for the leading-edge component as observed in the recent inspections of the SME vessel coil guide.

Measurements and observations of erosion in the SME showed the upstream coil lead-in completely removed, tank floor erosion in Region 1 of about 3/8-in, and floor erosion in Region 2 of about 1/16-1/8-in. The wall shear stresses shown in Table 3 indicate that the maximum shear stress expected in the MFT (103 rpm) in Region 1 is slightly less than that observed in Region 2 of the SME calculation $(130 \mathrm{rpm})$. Therefore, while the coil guide lead-in might be eroded in the MFT, the tank floor would not be eroded any more than the degree observed in Region 2 of the SME, viz., no more than 1/8-in. A linear extrapolation of the data based on wall shear stress would indicate an erosion of about 0.05 in in the MFT in Region 1 and none in Region 2. Table 3 also indicates that virtually no erosion from wall abrasion would be expected for impeller speeds of $65 \mathrm{rpm}$. 
The erosion patterns due to particle collision against the wall surface of the coil guide are qualitatively compared for these three flow conditions as shown in Fig. 19. Typical trajectories of the solid particles transported by viscous fluid are shown in Fig. 20. The results shown that the tendency of the particle impingement sites on the lower boundary surface of the coil guide becomes larger due to the gravity effect of solids as the mixed fluid speed becomes lower.

Table 3. Maximum wall shears for three major erosion locations observed by the recent SME inspections and CFD modeling results for SME/MFT coil guide (Refer to Fig. 18)

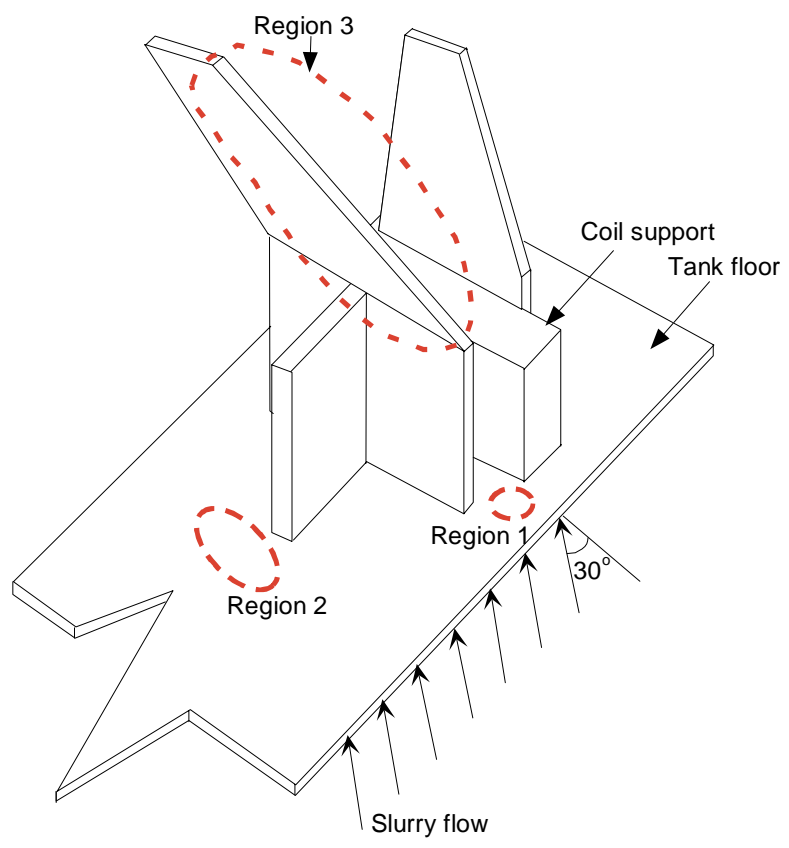

\begin{tabular}{|c|c|c|c|}
\hline $\begin{array}{c}\text { Slurry velocity magnitude for } \mathbf{3 0}^{\circ} \\
\text { incident into coil guide region } \\
\text { (agitator speed) }\end{array}$ & $\begin{array}{c}\text { Max. wall } \\
\text { shear at } \\
\text { Region 1 }\end{array}$ & $\begin{array}{c}\text { Max. wall } \\
\text { shear at } \\
\text { Region 2 }\end{array}$ & $\begin{array}{c}\text { Max. wall } \\
\text { shear at } \\
\text { Region 3 }\end{array}$ \\
\hline $0.65 \mathrm{~m} / \mathrm{sec}(65 \mathrm{rpm})$ & $39 \mathrm{~Pa}$ & $29 \mathrm{~Pa}$ & $41 \mathrm{~Pa}$ \\
\hline $1.3 \mathrm{~m} / \mathrm{sec}(103 \mathrm{rpm})$ & $87 \mathrm{~Pa}$ & $65 \mathrm{~Pa}$ & $107 \mathrm{~Pa}$ \\
\hline $1.8 \mathrm{~m} / \mathrm{sec}(130 \mathrm{rpm})$ & $127 \mathrm{~Pa}^{\star \star}$ & $96 \mathrm{~Pa}^{\star \star \star}$ & $169 \mathrm{~Pa}^{\star}$ \\
\hline
\end{tabular}

Note: *Severe damage due to erosion (observed)

** High erosion (observed)

*** Visibly noticeable erosion (observed) 

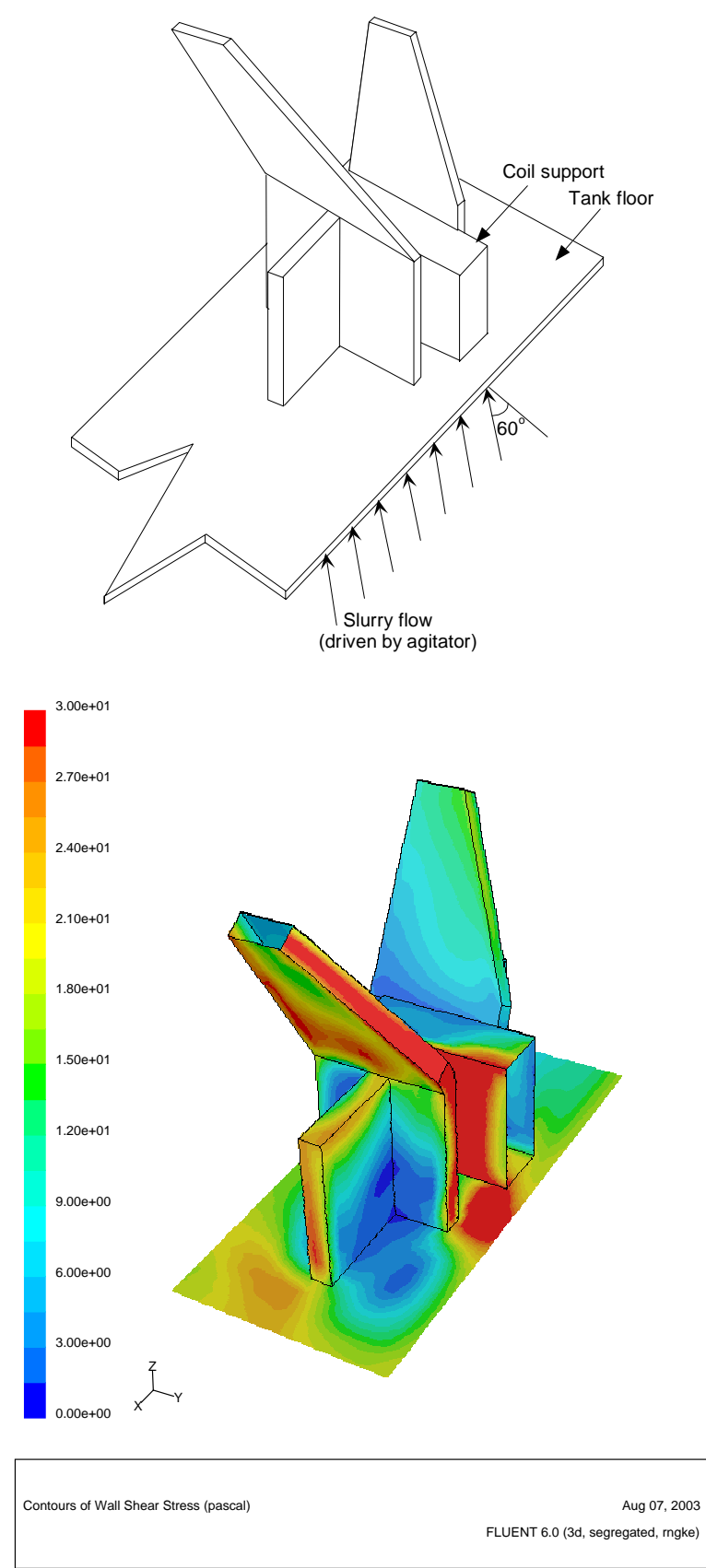

Figure 6. Wall shear distributions for $65 \mathrm{rpm}(0.65 \mathrm{~m} / \mathrm{sec})$ with $60^{\circ}$ flow incidence Case-A 

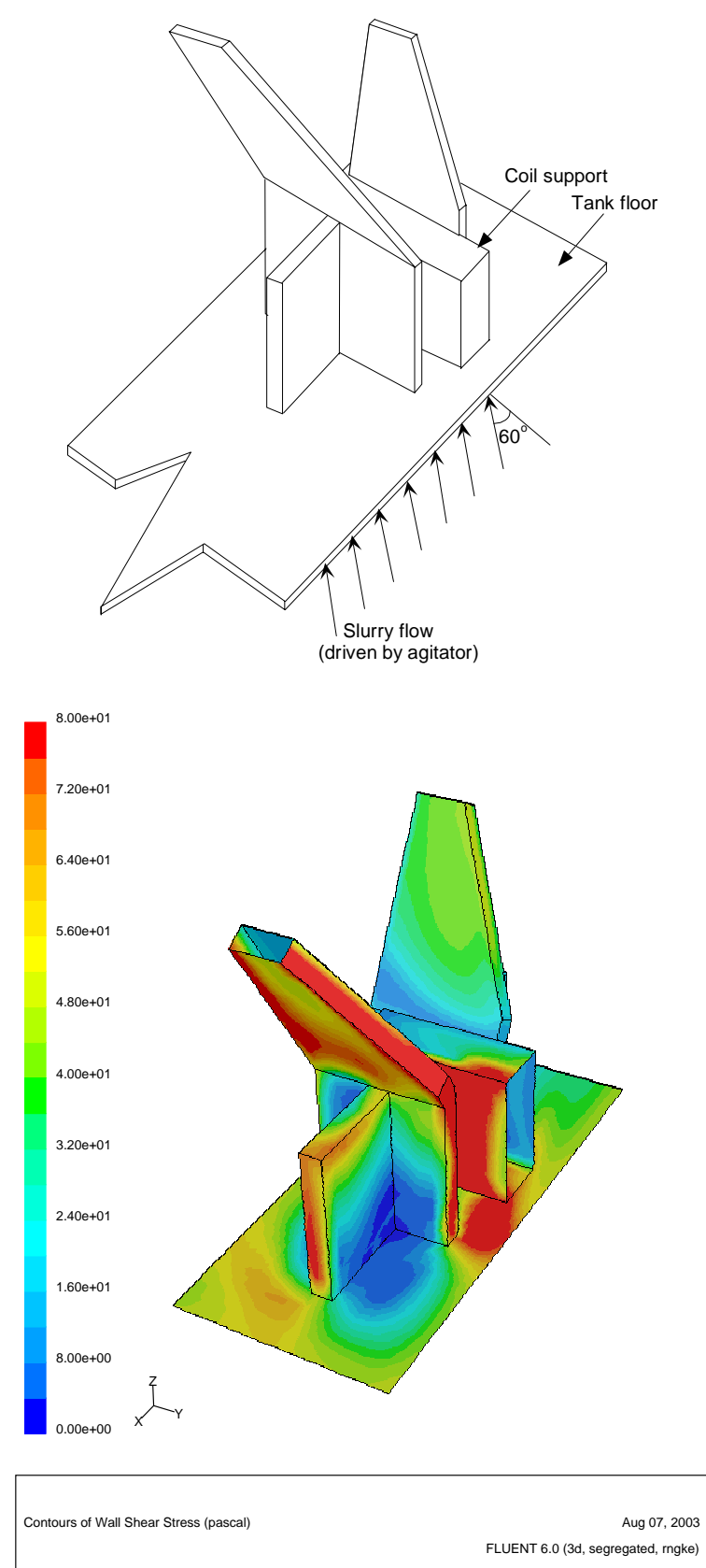

Figure 7. Wall shear distributions for $130 \mathrm{rpm}(1.5 \mathrm{~m} / \mathrm{sec})$ with $60^{\circ}$ flow incidence Case-A 

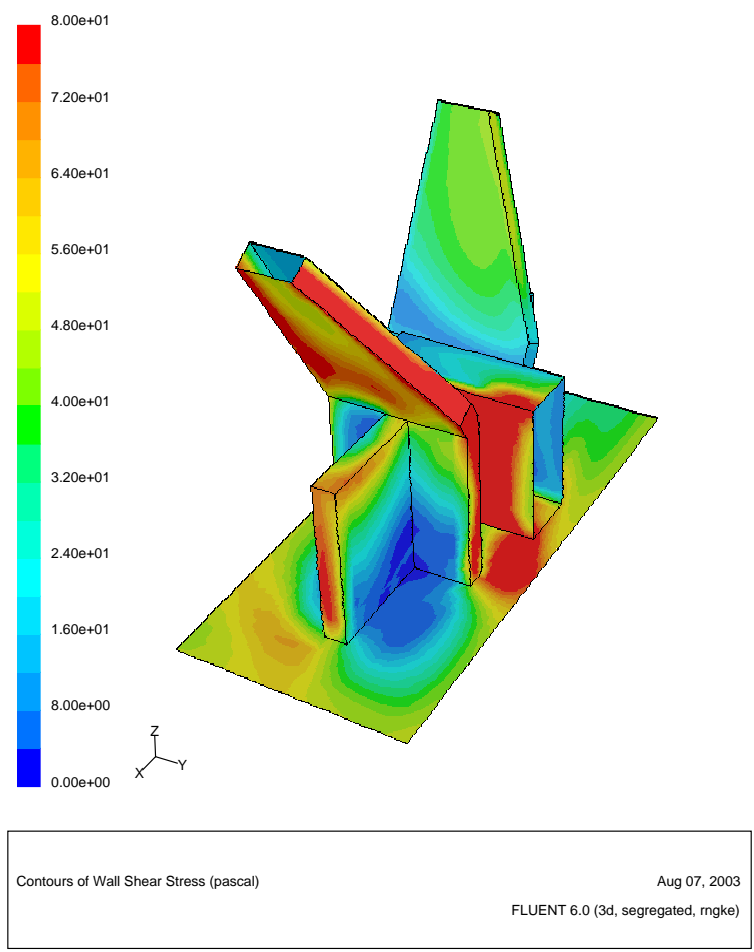

(60 $0^{\circ}$ incidence)

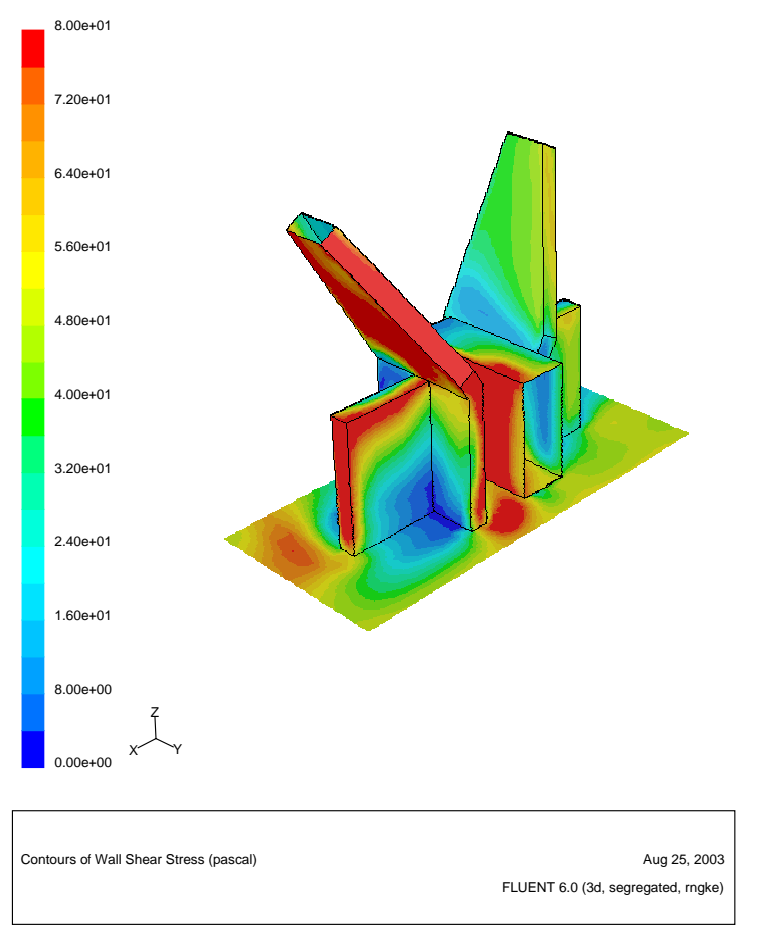

(30 $0^{\circ}$ incidence)

Figure 8. Comparison of wall shear distributions for $130 \mathrm{rpm}(1.5 \mathrm{~m} / \mathrm{sec})$ between $60^{\circ}$ and $30^{\circ}$ flow incidences - Case-A 

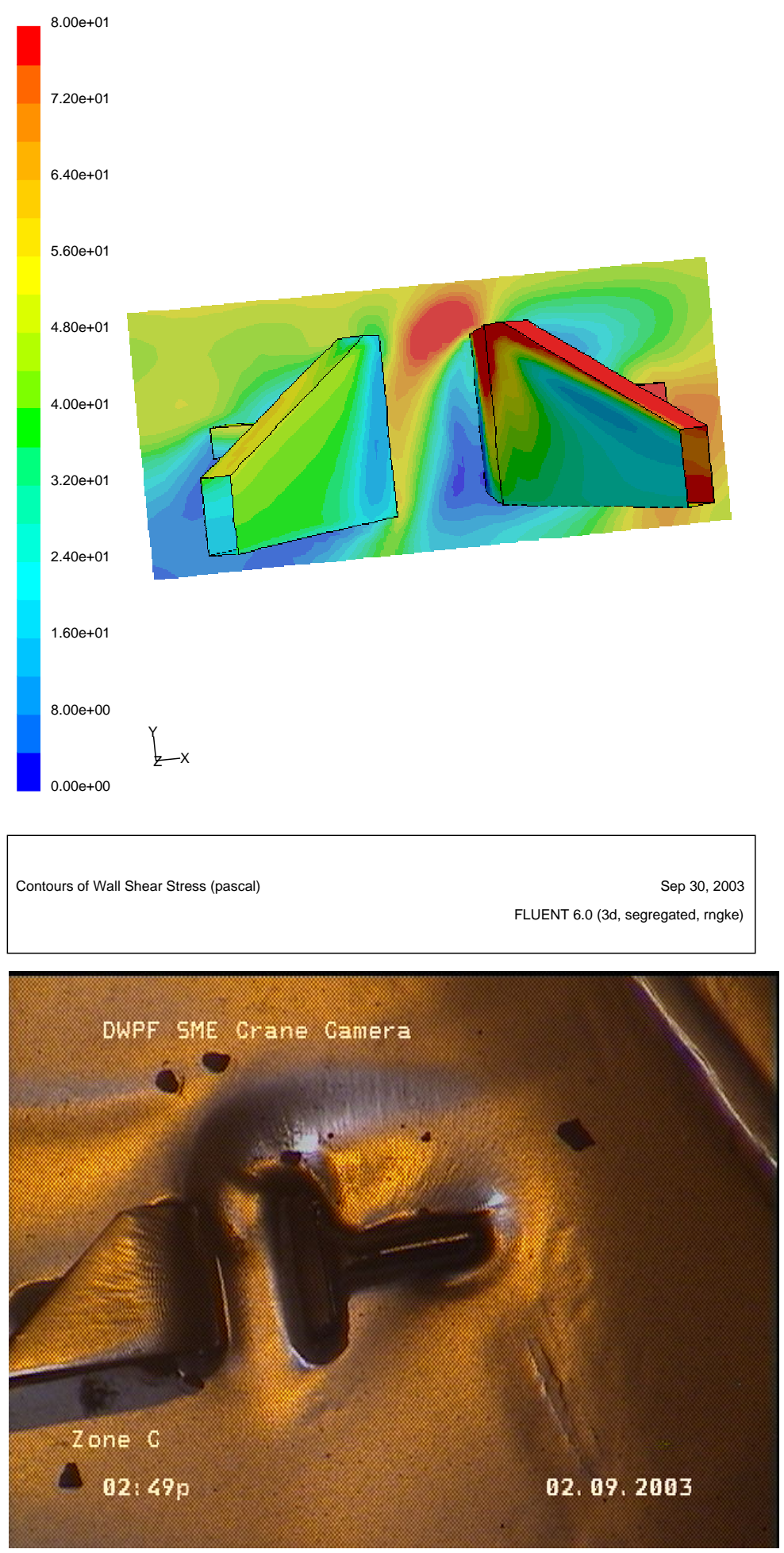

Figure 8a. Comparison of the predicted high wall shear indicated on the right lead-in plate (above) to the worn-away lead-in plate shown in the visual inspection photo (below) (the model predictions based on $130 \mathrm{rpm}$ and $30^{\circ}$ flow incidence) 

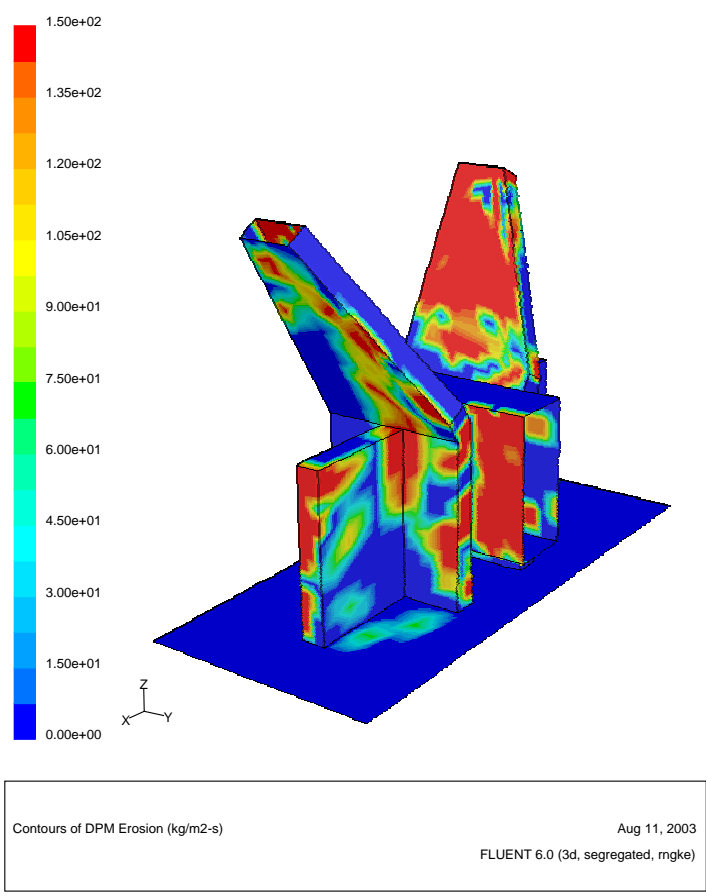

(65 rpm: $0.65 \mathrm{~m} / \mathrm{sec}$ )

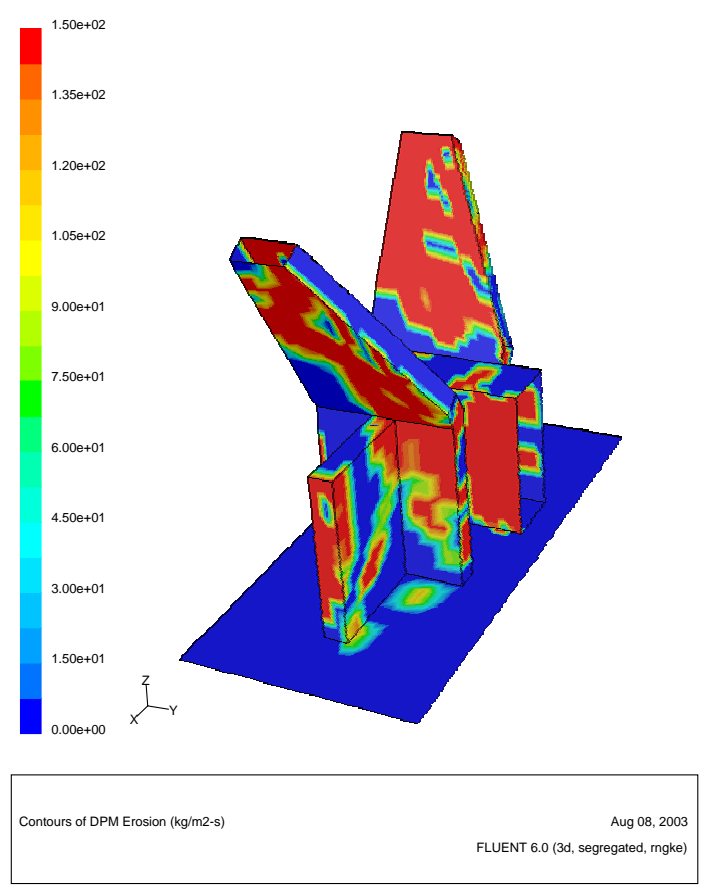

(130 rpm: $1.5 \mathrm{~m} / \mathrm{sec})$

Figure 9. Comparison of erosion patterns due to particle impingement for two different agitator speeds with $60^{\circ}$ incident angle into the coil guide area - Case-A 


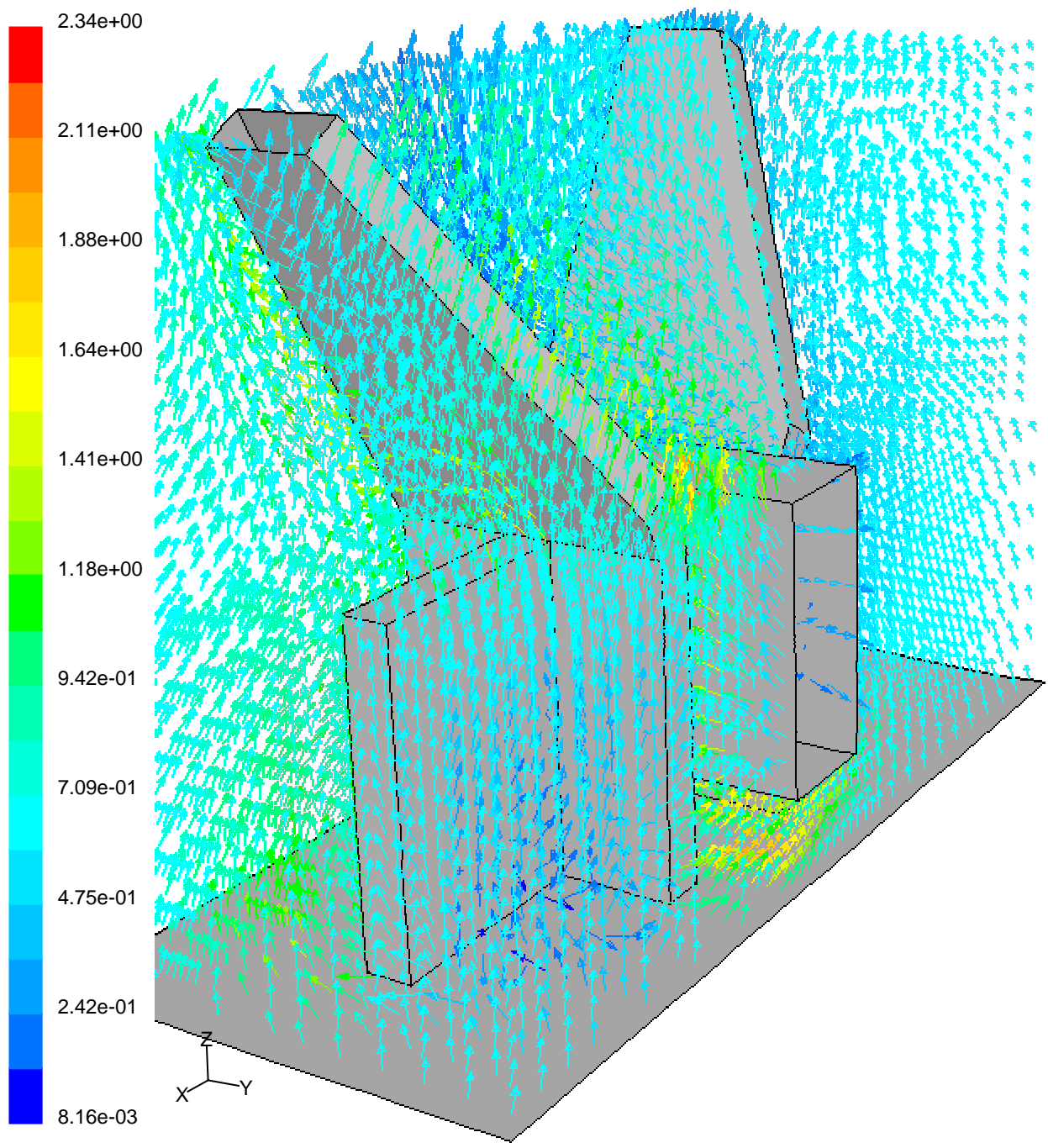

Figure 10. Flow patterns around the SME guide pin for $30^{\circ}$ incident angle and $65 \mathrm{rpm}$ $(0.65 \mathrm{~m} / \mathrm{sec})$ - Case-A 


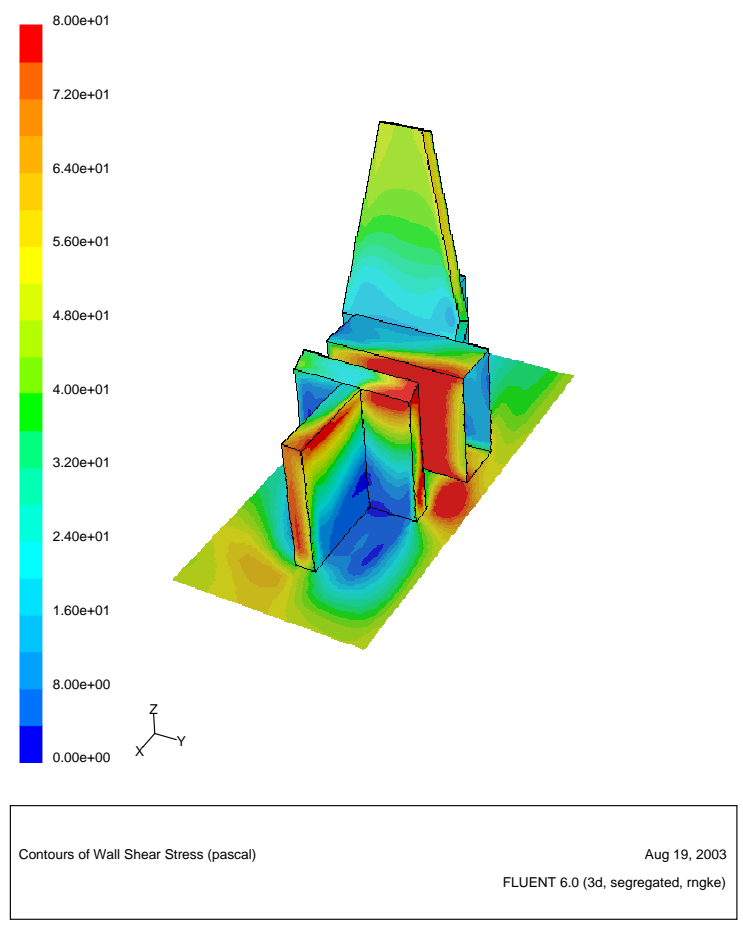

$\left(60^{\circ}\right.$ incidence angle of slurry flow into the guide pin)
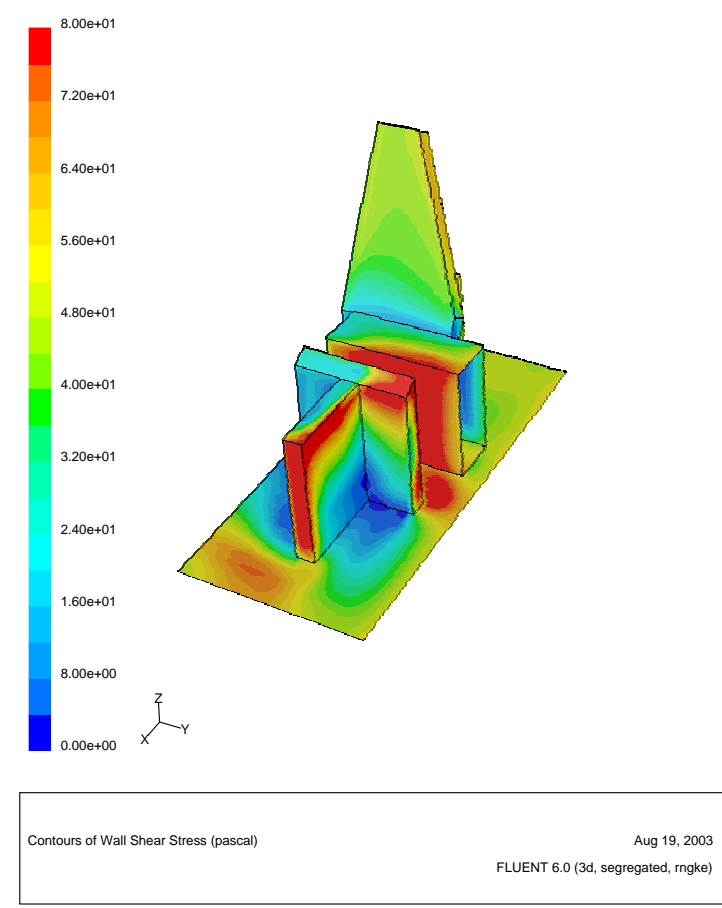

( $30^{\circ}$ incidence angle of slurry flow into the guide pin)

Figure 11. Comparison of wall shear distributions for two incident angles of slurry flow fields created by $130 \mathrm{rpm}(1.5 \mathrm{~m} / \mathrm{sec})$ agitator speed under the damaged coil guide geometry (Case-B) 


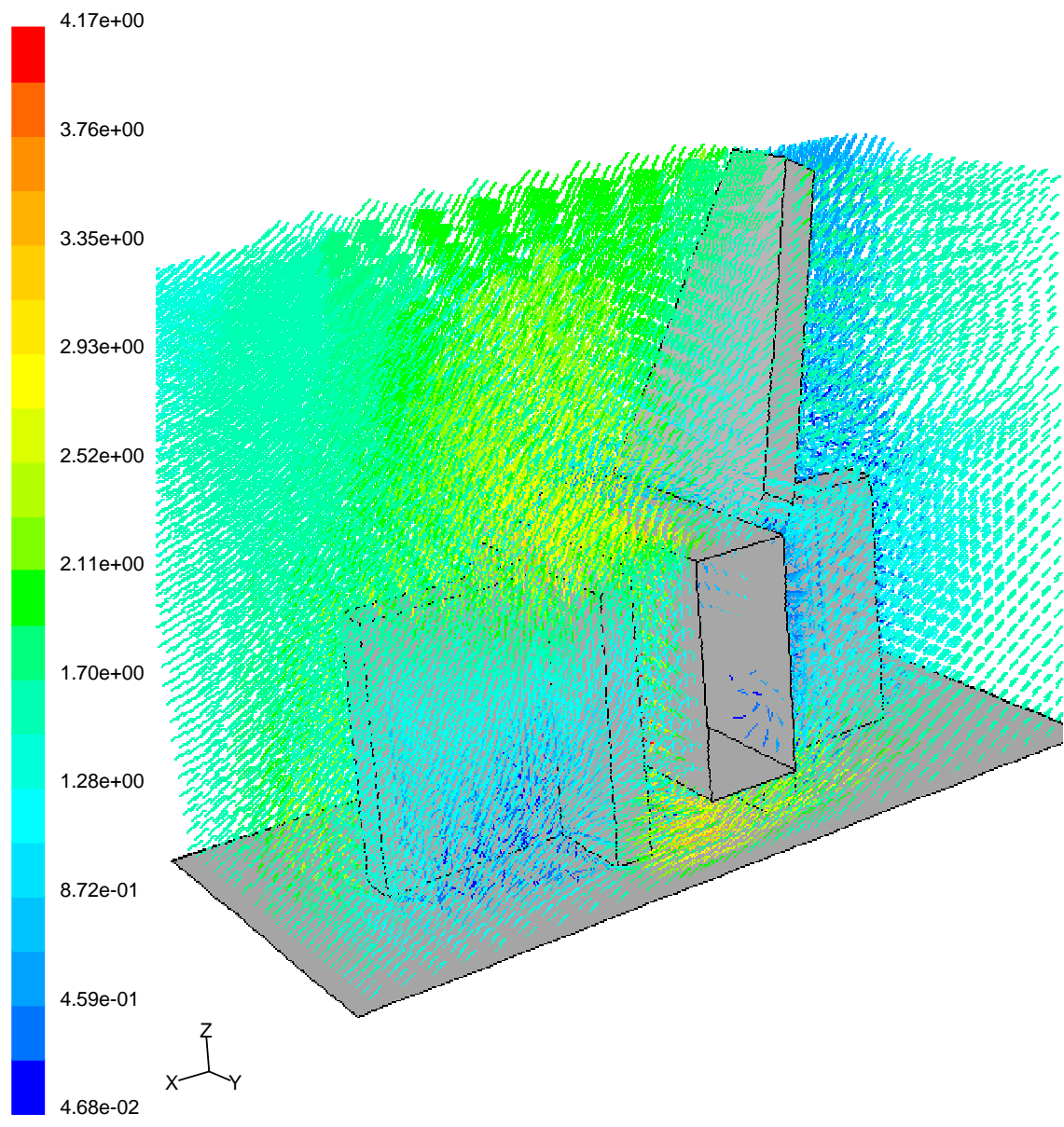

Figure 12. Flow patterns around the one-pin SME guide for $130 \mathrm{rpm}$ with $60^{\circ}$ incidence $(1.5 \mathrm{~m} / \mathrm{sec})$ - Case-B 

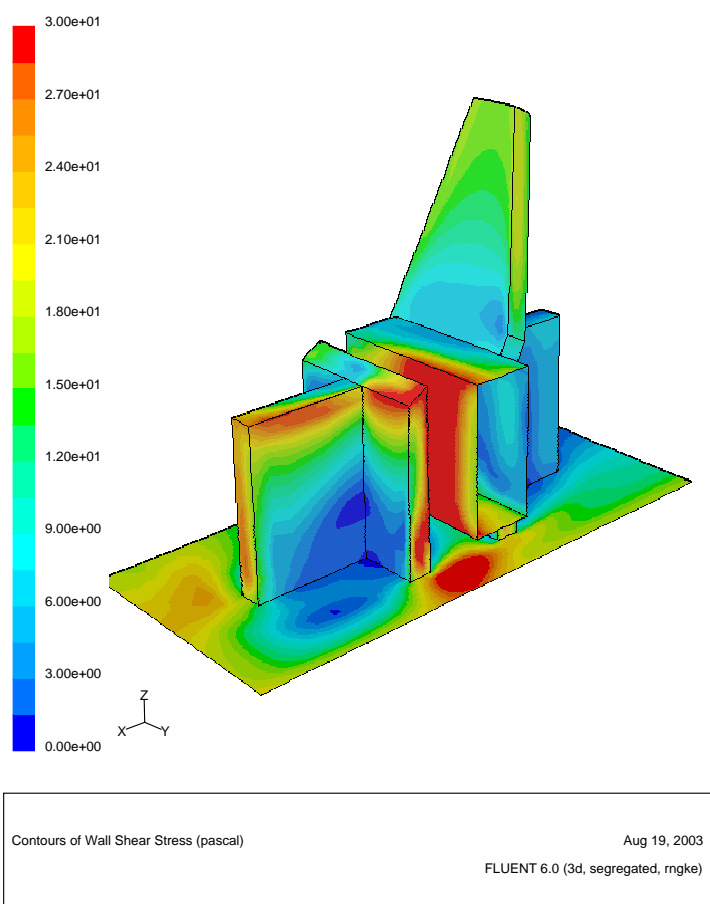

$\left(60^{\circ}\right.$ incidence angle of slurry flow into the guide pin)
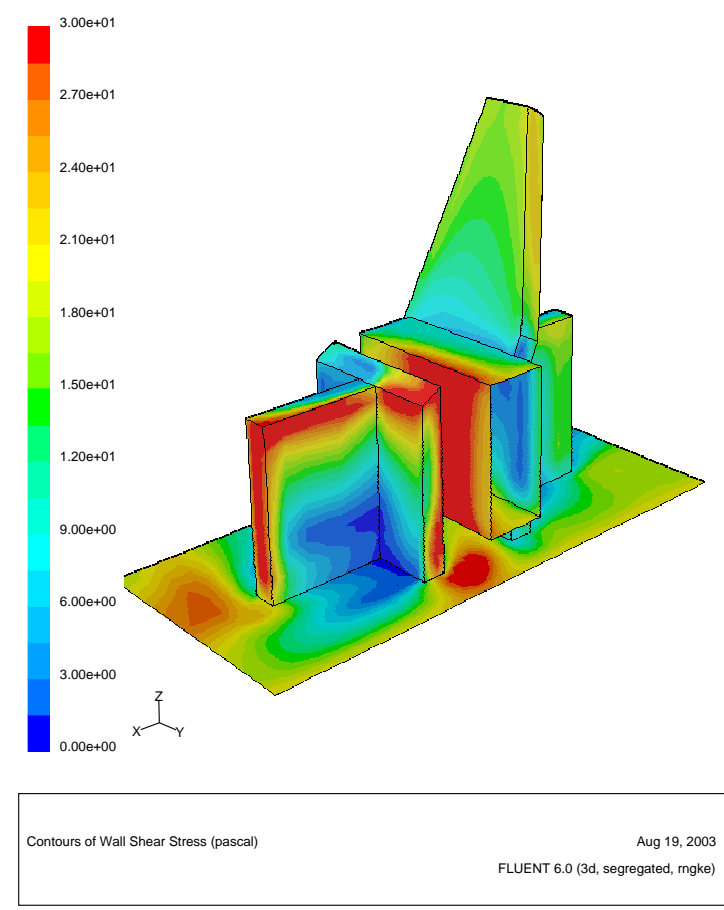

( $30^{\circ}$ incidence angle of slurry flow into the guide pin)

Figure 13. Comparison of abrasive wall shears for two different incident angles of slurry flow into the guide pin under the flow field created by $65 \mathrm{rpm}$ agitator speed in the damaged coil guide (Case-B) 


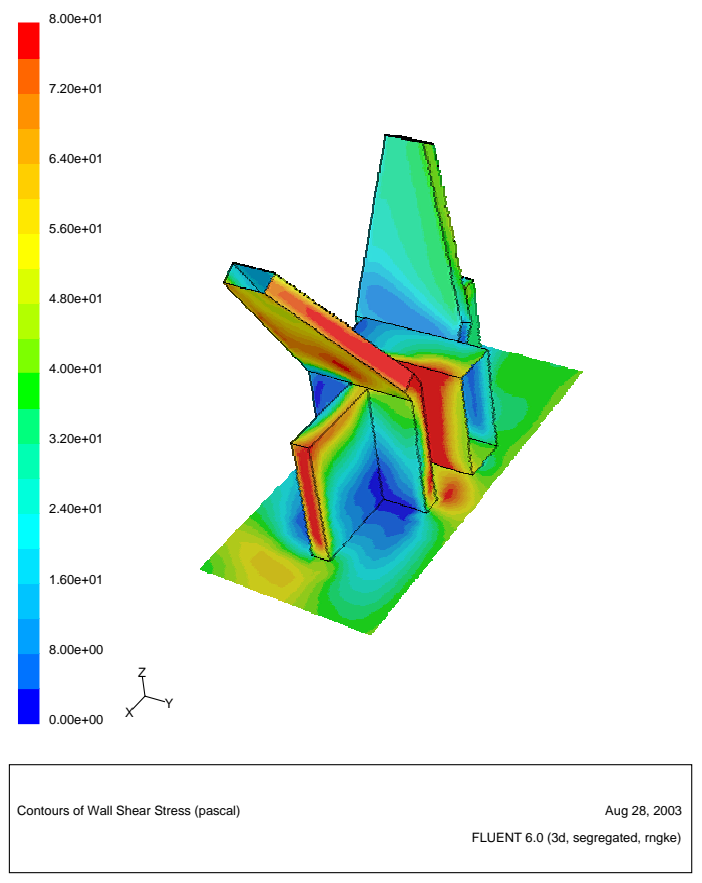

(Case-A geometry)

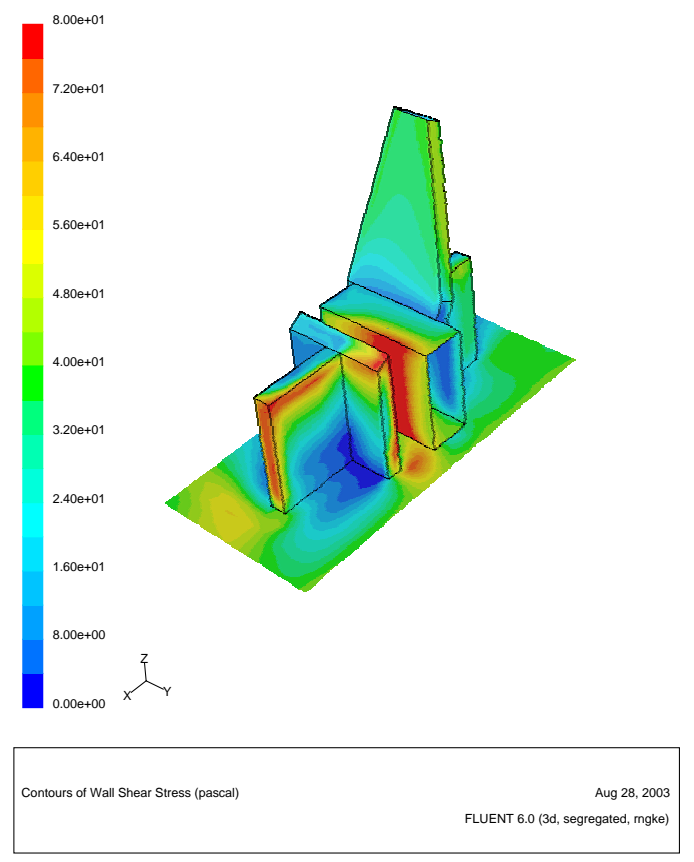

(Case-B geometry)

Figure 14. Comparison of wall shears between two cases for $103 \mathrm{rpm}$ with $30^{\circ}$ incidence angle of slurry flow into the guide pin $(1.2 \mathrm{~m} / \mathrm{sec})$ 

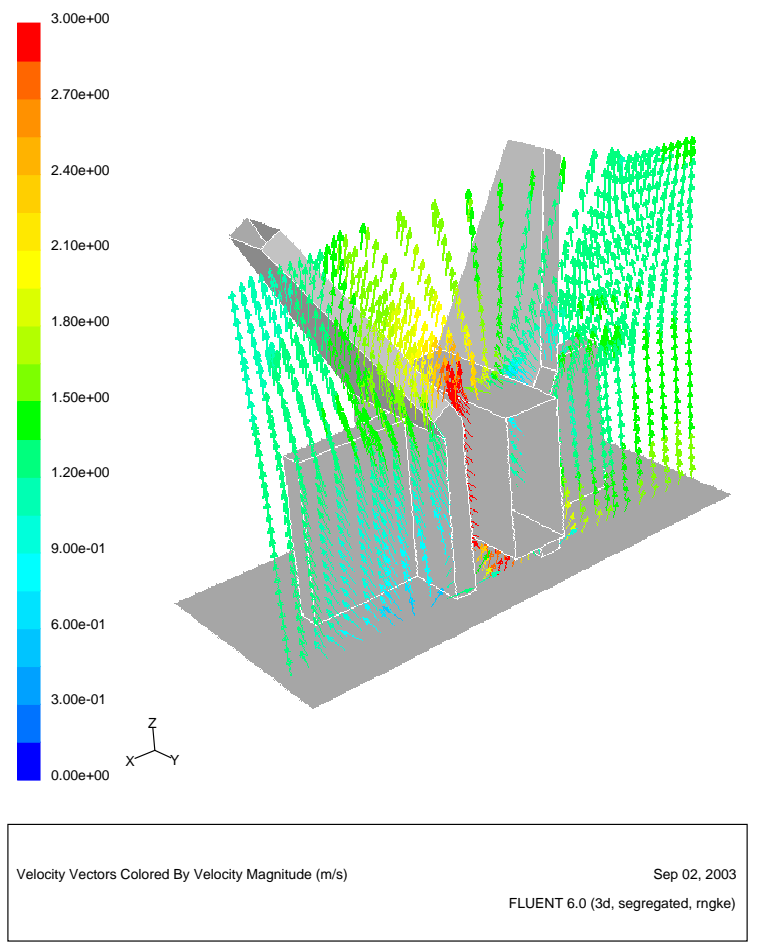

(Case-A)

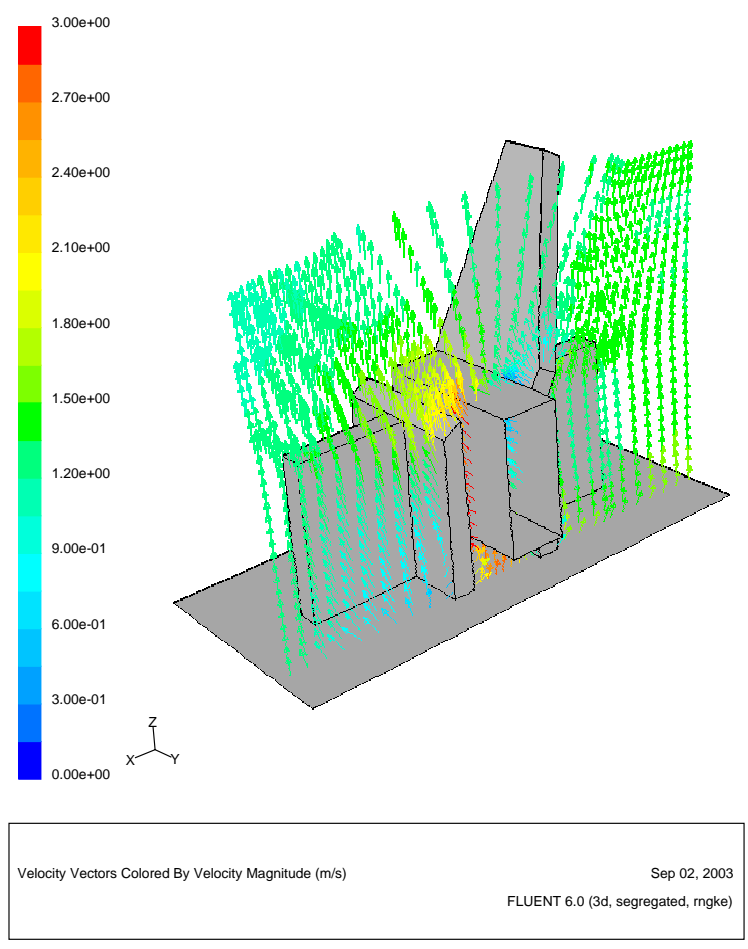

(Case-B)

Figure 15. Comparison of flow patterns between two cases for $103 \mathrm{rpm}$ with $30^{\circ}$ incidence angle of slurry flow into the guide pin $(1.2 \mathrm{~m} / \mathrm{sec})$ 

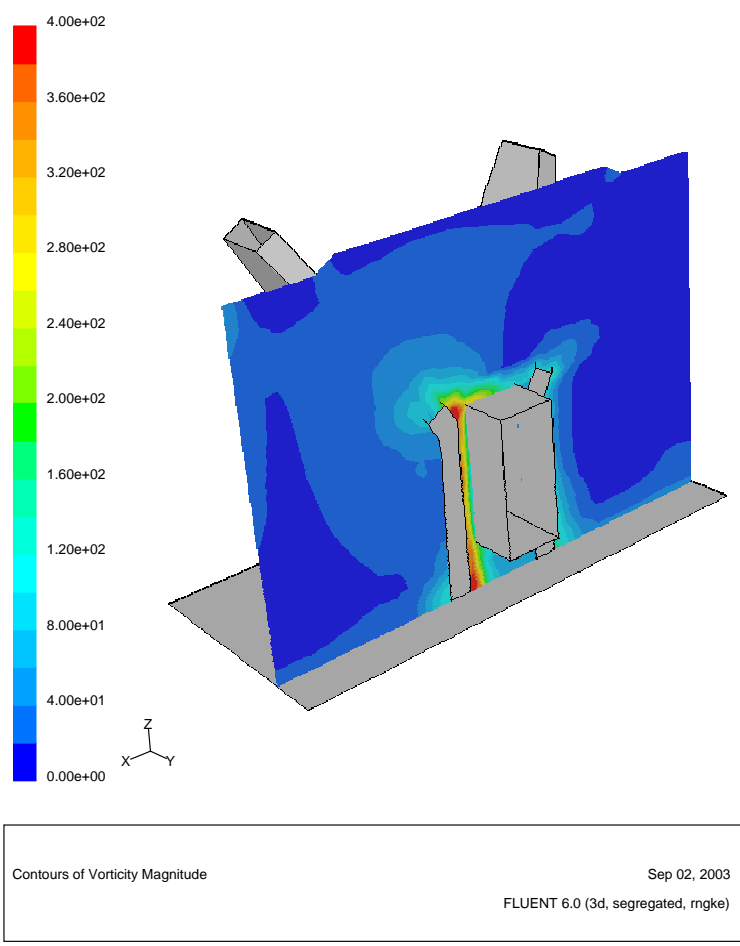

(Case-A)

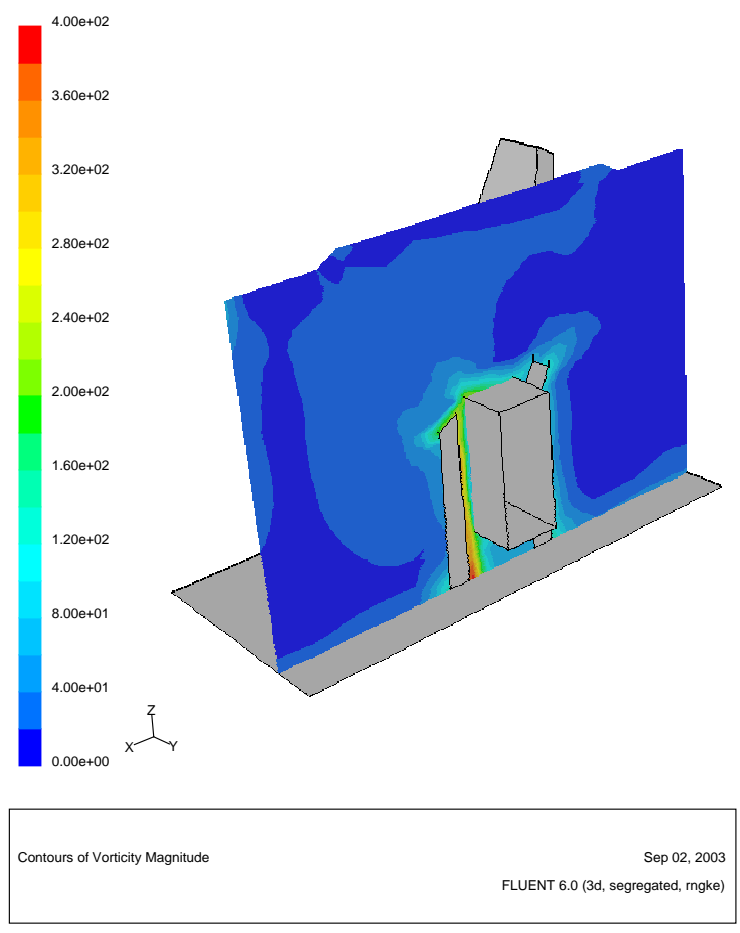

(Case-B)

Figure 16. Comparison of flow rotations between two cases for $103 \mathrm{rpm}$ with $30^{\circ}$ incidence angle of slurry flow into the guide pin $(1.2 \mathrm{~m} / \mathrm{sec})$ 

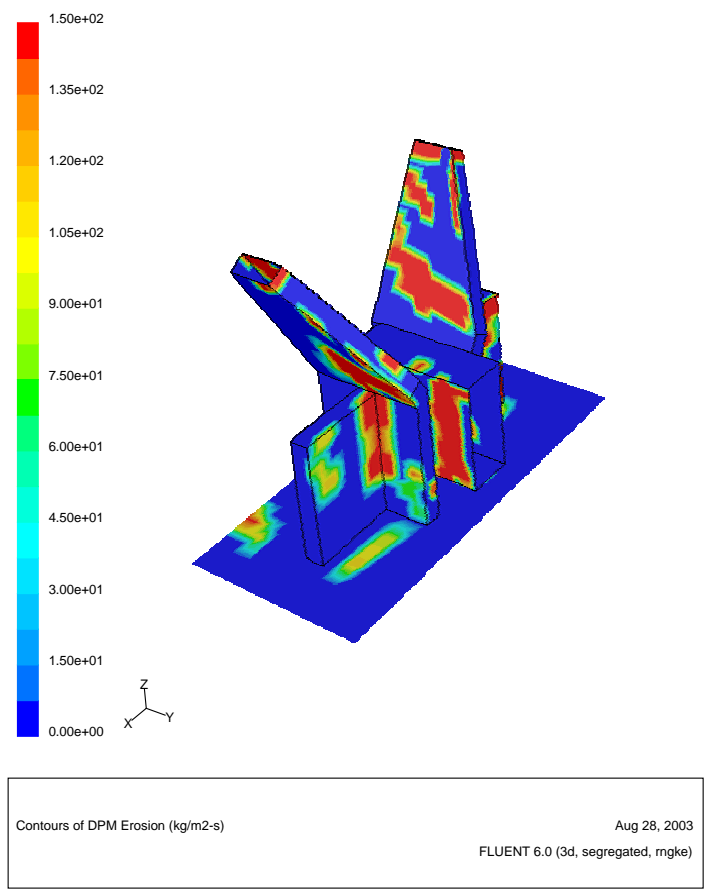

(Original geometry: Case-A)

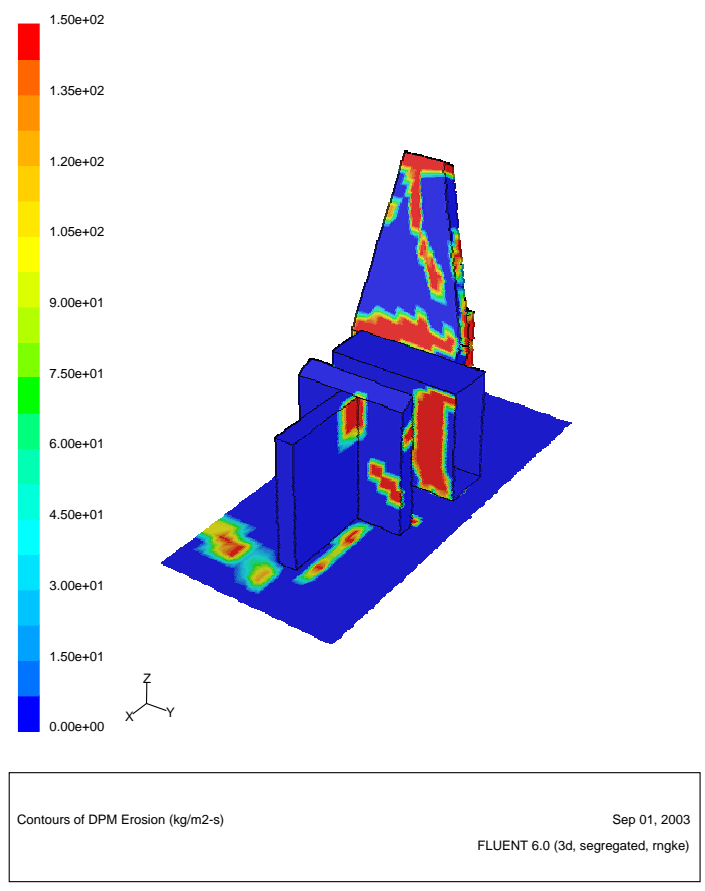

(The damaged geometry: Case-B)

Figure 17. Comparison of erosion patterns due to the particle impingement for $103 \mathrm{rpm}$ with $30^{\circ}$ incidence angle of slurry flow into the guide pin $(1.2 \mathrm{~m} / \mathrm{sec})$ 

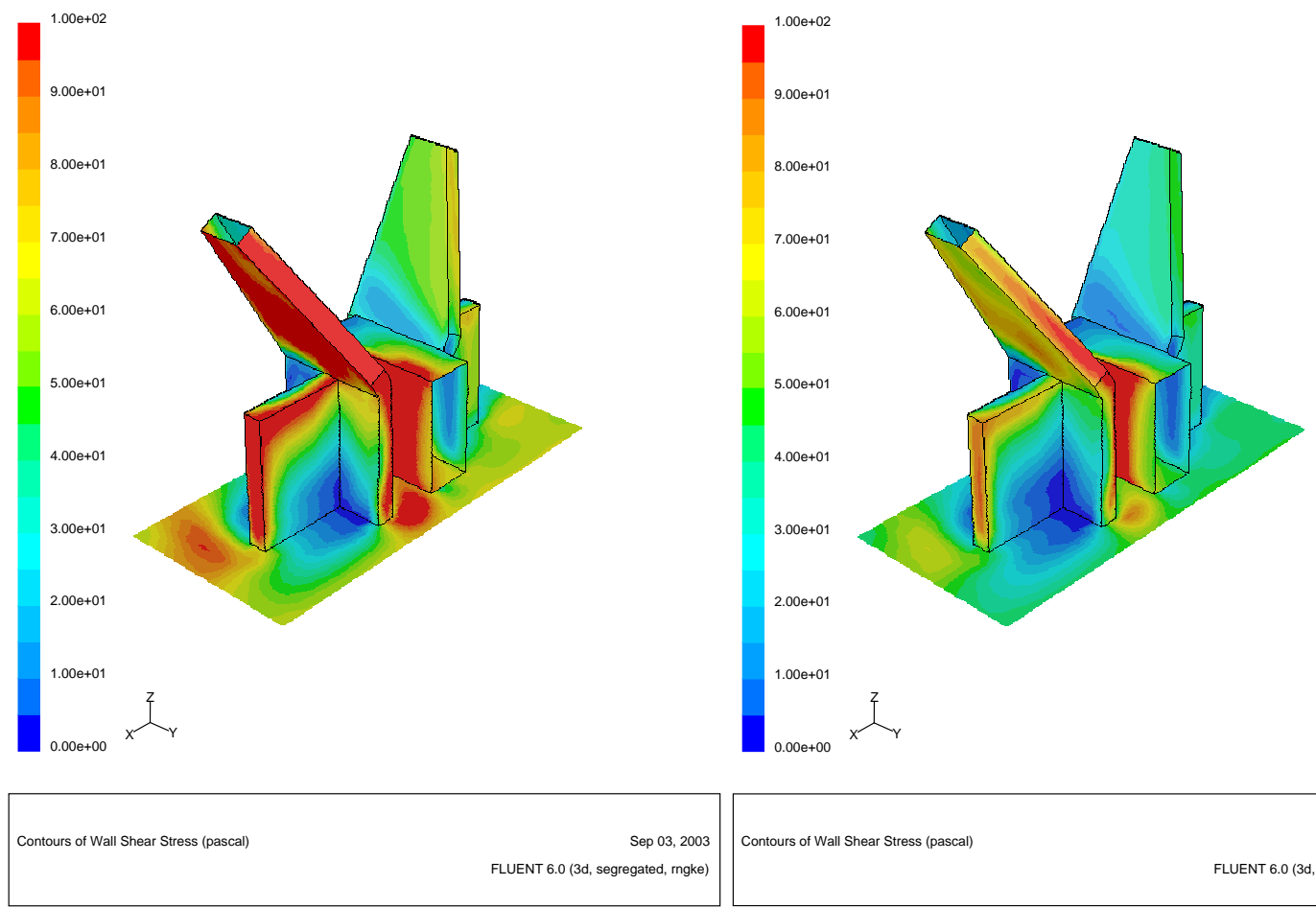

(130 rpm)
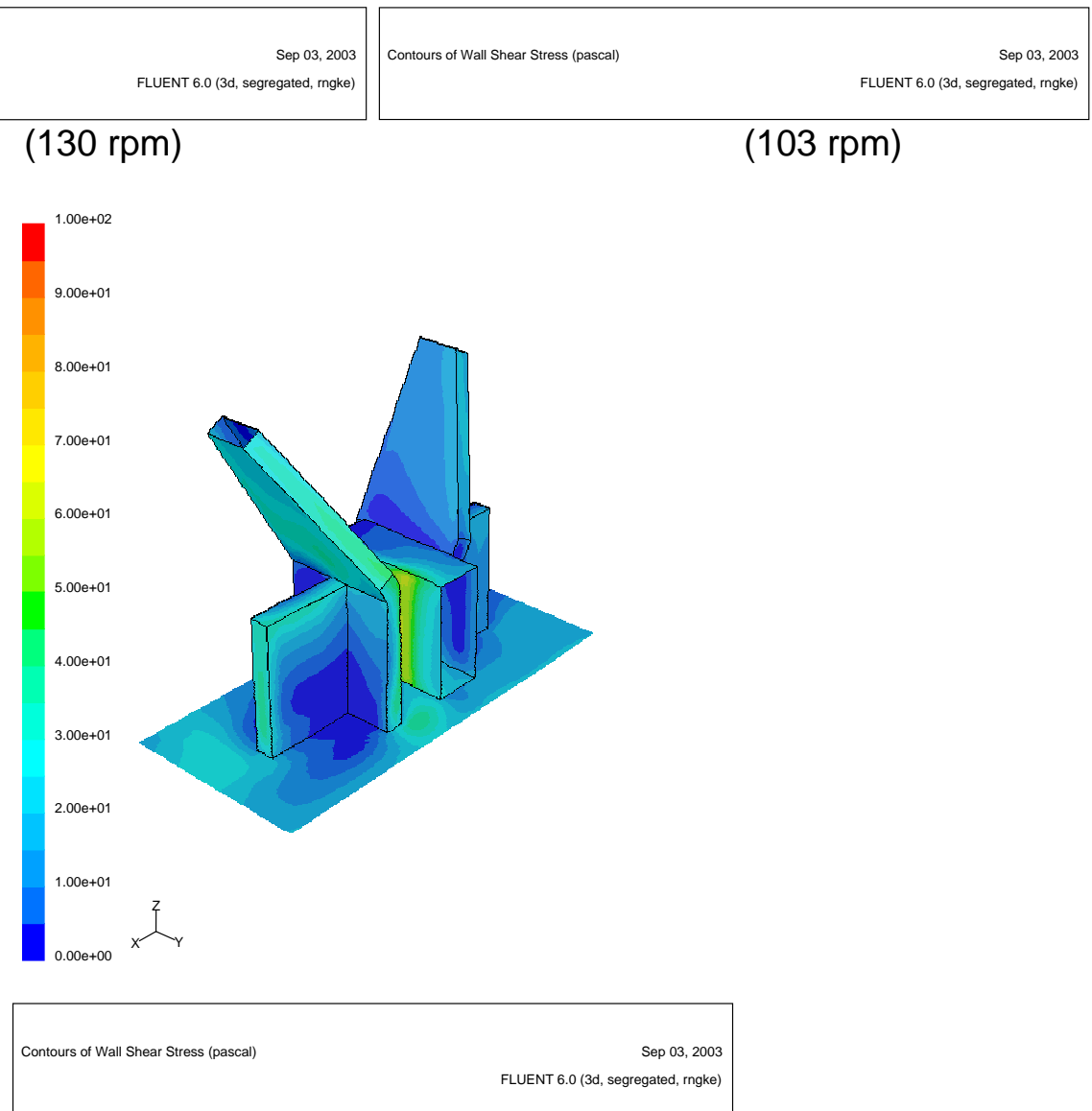

(65 rpm)

Figure 18. Comparison of abrasive wall shears between three different cases with $30^{\circ}$ incidence angle of slurry flow into the guide pin - Case-A 


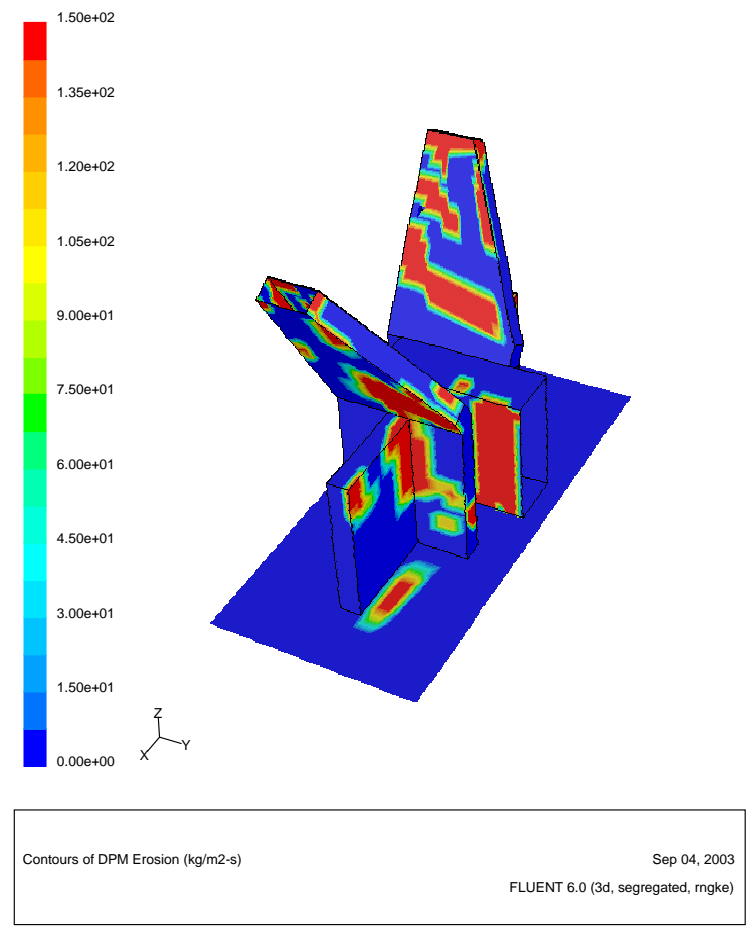

(130 rpm: $1.8 \mathrm{~m} / \mathrm{sec})$
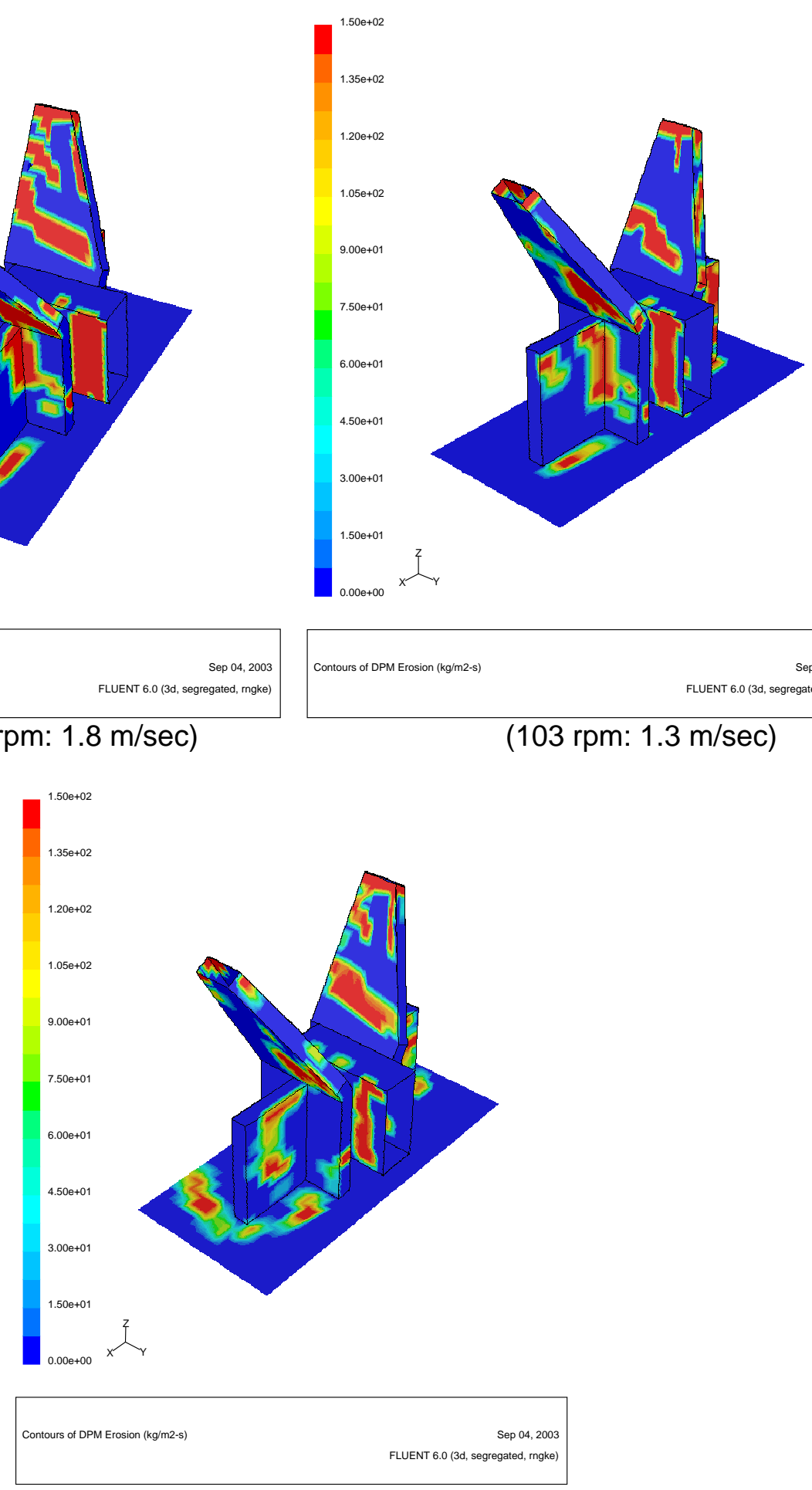

(65 rpm: $0.65 \mathrm{~m} / \mathrm{sec}$ )

Figure 19. Erosion distributions due to the particle impingement for the flow fields created by three different agitator speeds with $30^{\circ}$ incidence angle of slurry flow into the guide pin area under the original coil guide geometry (Case-A) 


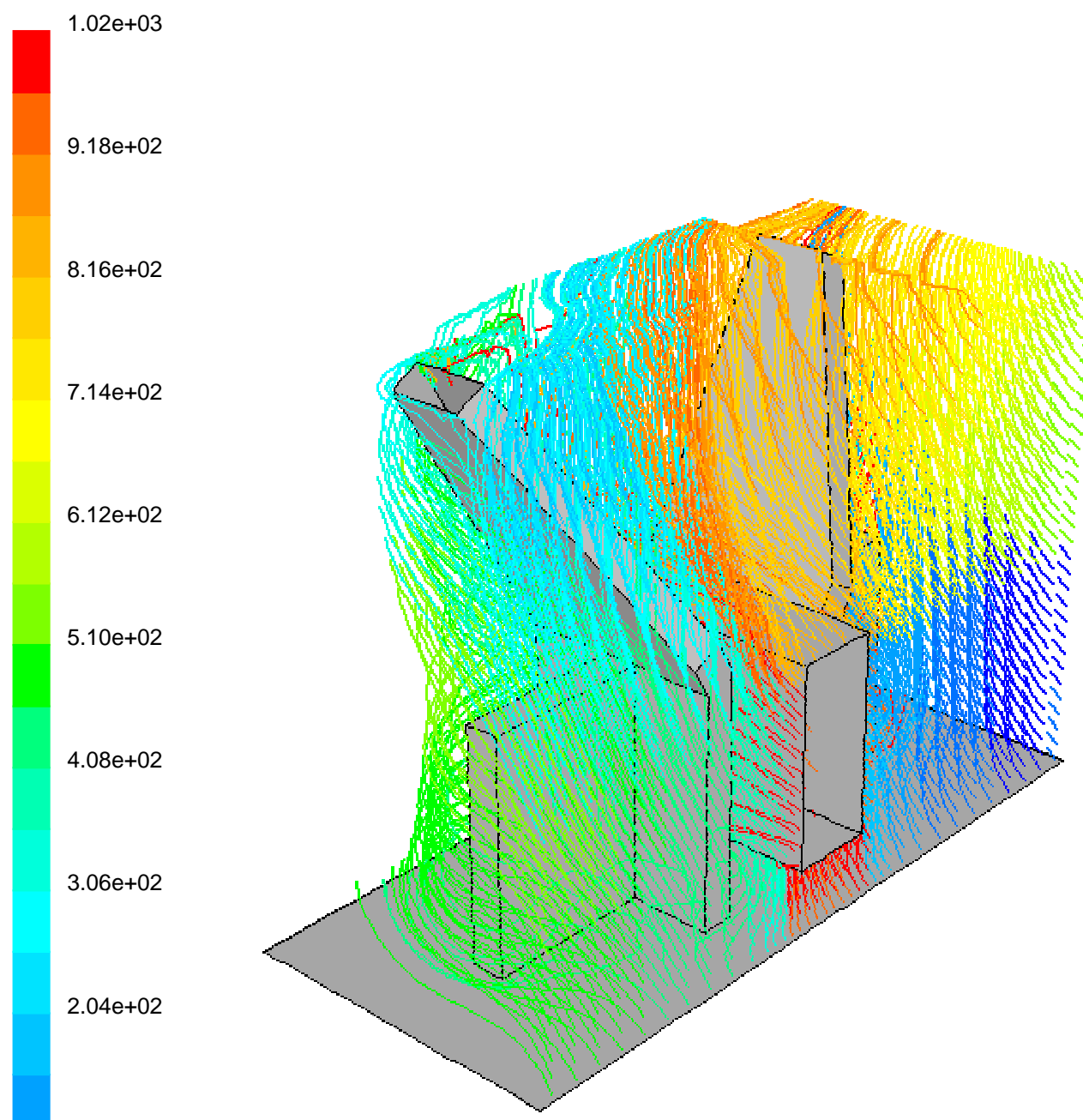

$1.02 \mathrm{e}+02$

$0.00 \mathrm{e}+00$<smiles>[X]C([X])[X]</smiles>

Figure 20. Particle trajectories for $65 \mathrm{rpm}(0.65 \mathrm{~m} / \mathrm{sec})$ around the coil guide with $30^{\circ}$ incidence angle of slurry flow into the guide pin of the original geometry (Case-A) 
Page: $\quad 30$ of 34 


\section{Summary and Conclusions}

This report presents the application of computational fluid dynamics (CFD) methods to qualitative estimate of the erosion phenomena expected in the actual SME/MFT process facilities.

The results show that primary locations of the highest erosion due to the abrasive wall erosion are at the leading edge of the guide, the tank floor below the insert plate of the coil guide, and the upstream side plate of the top lead-in plate. The modeling results are in good agreement with the visual observations done by the recent SME inspections [11]. A series of the modeling results indicates that potential high erosion sites for the current geometry of the coil guide are caused primarily by the abrasive wall shear rather than particle impingement since the mixed fluid containing the solids has high viscosity of about $10 \mathrm{cp}$ and the present coil guide geometry has a large open space without any sudden change of flow direction. These two conditions tend to prevent the high collision rates of the solid particles against the wall boundary.

Based on the modeling domain defined in Fig. 2 and the operating conditions shown in Table 1, the erosion evaluations for two geometrical cases and three different operating conditions were performed to provide information on erosion damage causes of the coil guide surfaces in SME/MFT vessels. The computational results of the erosion study were estimated qualitatively in terms of flow patterns and erosion characteristics since the modeling predictions could not be benchmarked against the actual test data in a quantitative way.

The results show:

1. The modeling predictions for the high erosion sites of the coil guide are in good agreement with the observed sites of the recent inspections of the SME vessel done by DWPF Engineering.

2. Potential damage sites due to the abrasive wall erosion are at the upstream regions of the coil guide support as shown in Table 3.

3. A series of the modeling results demonstrates that when the MFT agitator operates between $65 \mathrm{rpm}$ and $103 \mathrm{rpm}$, the upstream coil guide lead-in plate will be damaged by erosion, but maximum wall shear for the tank floor below the coil support tab is about $87 \mathrm{~Pa}$, which is well below the $169 \mathrm{~Pa}$ shear that resulted in serious erosion of the leading edge component as observed in the recent inspections of the SME vessel.

These findings are consistent with the observed damage to the coil guide of the SME vessel. The results show that the potential for erosion of the MFT floor is much smaller than the SME due to the reduction in impeller speed from $130 \mathrm{rpm}$ to $103 \mathrm{rpm}$. Only minor wear is predicted to the region of the tank floor in the area of the coil guide. Inspection of the MFT floor in the vicinity of the coil guide is not required. 


\section{References}

1. Neuville, J. R., Taylor, G., Dimenna, R. A., and Lee, S. Y., "MFT/SME CFD Modeling", Interoffice Memorandum, CBU-WSE-2003-00111, June 9, 2003.

2. Lee, S. Y., and Dimenna, R. A., "Erosion Analysis for the Misaligned U2 Nozzle and Its Connector Block", WSRC-TR-2002-00352, April 2002.

3. Lee. S. Y. and Dimenna, R. A., "Design Analysis For A Scaled Erosion Test", WSRCTR-2001-00591, SRT-RPP-2001-00227, Rev. 0, April 2002.

4. Duignan, M. R. and Lee, S. Y., "RPP-WTP Slurry Wear Evaluation: Literature Review", Savannah River Technology Center, WSRC-TR-2001-00156, SRT-RPP2001-00033, March 21, 2001.

5. Burstein, G. T. and Sasaki, K., Effect of impact angle on the slurry erosion-corrosion of 304L stainless steel. Wear 240, 80-94, 2000.

6. MixSim 2.0 User's Guide, Fluent, Inc., Lebanon, New Hampshire, 2003.

7. S.L. Tiberia, C.T, Chandler, C.F. Jenkins, S.Y. Lee, A. P. Rangus, S.L.West, Independent Review of the Slurry Mix Evaporator Repairs, CBU-WSE-2003-0050, March 2003.

8. FLUENT, Fluent, Inc., Lebanon, New Hampshire, 1998.

9. H. Schlichting, Boundary Layer Theory, McGraw-Hill Book Company, New York, 1967.

10. Reference Bechtel Drawing No. W752139 (Bumper Guides for Coil Supports), Bechtel/E. I. Dupont De NeMours \& Co. for U.S. Dept. of Energy, Savannah River Plant, South Carolina.

11. W.R. Hinz, Nondestructive Examination Condition Report, SRT-MTS-2003-60109, February 13, 2003.

12. Graf, W. H., Hydraulics of Sediment Transport, McGraw-Hill Book Company, New York, 1971.

13. Lee, S. Y. and Dimenna, R. A., "Validation Analysis for the Calculation of a Turbulent Free Jet in water Using CFDS-FLOW3D and FLUENT (U)", WSRC-TR-95-0170, May 1995.

14. Mishra, A. and Finnie, I., "On the size effect in abrasive and erosive wear", Wear, vol. 65, pp. 359-373, 1981.

15. Neilson, J. H. and Gilchrist, A., "An analytical and experimental investigation of the velocities of particles entrained by the gas flow in nozzles", J. of Fluid Mech., vol. 33, pp. 131-149, 1968.

16. Roco, M.C. and Cader, T., "Energy approach for wear distribution in slurry pipelines", Jap. Journal of Multiphase Flow, vol. 4, pp. 2-20, 1990.

17. Kay, J. M. and Nedderman, R. M., Fluid Mechanics and Transfer Processes, Cambridge University Press, Cambridge, 1985.

18. W. M. Kays and M. E. Crawford, Convective Heat and Mass Transfer, Second Edition, McGraw-Hill Book Company, New York, 1980. 
Date: $\quad 4 / 5 / 2004$

EROSION MODELING ANALYSIS FOR DWPF MFT/SME TANKS

Page: $\quad 34$ of 34

19. Humphrey, J. A. C., "Fundamentals of Fluid Motion in Erosion by Solid Particle Impact", Int. J. of Heat and Fluid Flow, vol. 11, No. 3, pp. 170-195, 1990. 